\title{
Mono- vs. bi-metallic assembly on a bulky bis(imino)terpyridine framework: a combined experimental and theoretical study
}

\author{
Yohan D. M. Champouret, ${ }^{a}$ Jean-Didier Maréchal,,${ }^{a, b}$ Ishaq Dadhiwala,${ }^{a}$ John Fawcett, ${ }^{a}$ Donna Palmer, ${ }^{a}$ \\ Kuldip $\operatorname{Singh}^{a}$ and Gregory A. Solan*a
}

Received 14th November 2005, Accepted 6th February 2006

First published as an Advance Article on the web 22nd February 2006

DOI: 10.1039/b516083a

The bis(imino)terpyridine ligands, 6, 6" $-\left\{\left(2,6-i-\mathrm{Pr}_{2} \mathrm{C}_{6} \mathrm{H}_{3}\right) \mathrm{N}=\mathrm{CR}\right\}_{2}-2,2^{\prime}: 6^{\prime}, 2^{\prime \prime}-\mathrm{C}_{15} \mathrm{H}_{9} \mathrm{~N}_{3}(\mathrm{R}=\mathrm{H} \mathbf{L 1}, \mathrm{Me}$ L2), have been prepared in high yield from the condensation reaction of the corresponding carbonyl compound with two equivalents of 2,6-diisopropylaniline. The molecular structure of $\mathbf{L} 2$ reveals a transoid relationship between the imino and pyridyl nitrogen groups throughout the ligand framework. Treatment of aldimine-containing $\mathbf{L 1}$ with one equivalent or an excess of $\mathrm{MX}_{2}$ in $n$ - $\mathrm{BuOH}$ at $110{ }^{\circ} \mathrm{C}$ gives the mononuclear five-coordinate complexes, $\left[(\mathbf{L 1}) \mathrm{MX}_{2}\right](\mathrm{M}=\mathrm{Fe}, \mathrm{X}=\mathrm{Cl}$ 1a; $\mathrm{M}=\mathrm{Ni}, \mathrm{X}=\mathrm{Br}$ 1b; $\mathrm{M}=\mathrm{Zn}, \mathrm{X}=\mathrm{Cl} \mathbf{1 c}$ ), in which the metal centre occupies the terpyridine cavity and the imino groups pendant. Conversely, reaction of ketimine-containing $\mathbf{L} 2$ with excess $\mathrm{MX}_{2}$ in $n$-BuOH at $110{ }^{\circ} \mathrm{C}$ affords the binuclear complexes, [(L2) $\left.\mathrm{M}_{2} \mathrm{X}_{4}\right](\mathrm{M}=\mathrm{Fe}, \mathrm{X}=\mathrm{Cl}$ 3a; $\mathrm{M}=\mathrm{Ni}, \mathrm{X}=\mathrm{Br} \mathbf{3 b} ; \mathrm{M}=\mathrm{Zn}, \mathrm{X}=\mathrm{Cl}$ 3c), in which one metal centre occupies a bidentate pyridylimine cavity while the other a tridentate bipyridylimine cavity. ${ }^{1} \mathrm{H}$ NMR studies on diamagnetic 3c suggests a fluxional process is operational at ambient temperature in which the central pyridine ring undergoes an exchange between metal coordination. Under less forcing conditions (room temperature in dichloromethane), the monometallic counterpart of $\mathbf{1 b}\left[(\mathbf{L 2}) \mathrm{NiBr}_{2}\right](\mathbf{2 b})$ has been isolated which can be converted to $\mathbf{3 b}$ by addition of one equivalent of $(\mathrm{DME}) \mathrm{NiBr}_{2}\left(\mathrm{DME}=1,2\right.$-dimethoxyethane) in $n$ - $\mathrm{BuOH}$ at $110{ }^{\circ} \mathrm{C}$. Quantum mechanical calculations (DFT) have been performed on $\left[(\mathbf{L 1}) \mathrm{ZnCl}_{2}\right]$ and $\left[(\mathbf{L 2}) \mathrm{ZnCl}_{2}\right]$ for different monometallic conformations and show that $\mathbf{1 a}$ is the energetically preferred structure for $\mathbf{L} \mathbf{1}$ while there is evidence for dynamic behaviour in L2-containing species leading to bimetallic formation. Single-crystal X-ray diffraction studies have been performed on $\mathbf{1 a}, \mathbf{1 b}, \mathbf{1 c}, \mathbf{2 b}, \mathbf{3} \mathbf{a}, \mathbf{3} \mathbf{b}\left(\mathrm{H}_{2} \mathrm{O}\right)$ and $\mathbf{3 c}$.

\section{Introduction}

The application of 2,6-linked oligopyridine ligands, $\mathrm{C}_{5} \mathrm{H}_{4} \mathrm{~N}$ $\left(\mathrm{C}_{5} \mathrm{H}_{3} \mathrm{~N}\right)_{n} \mathrm{C}_{5} \mathrm{H}_{4} \mathrm{~N}(n=2-7)$, in coordination chemistry is now well established with mono-, double- or triple-stranded helicates being a feature of the structural types. ${ }^{1}$ For example quinquepyridine $(n=3)$ can readily form homobimetallic salts of the type [(quinquepyridine $\left.)_{2} \mathrm{M}_{2}\right]^{n+}$ with a variety of $3 \mathrm{~d}$ metal ions including cobalt, $^{2}$ nickel $^{3}$ and copper. ${ }^{4}$

We have been interested recently in developing oligopyridine ligands featuring sterically demanding imino end-groups, $\operatorname{ArN}=\mathrm{CR}\left(\mathrm{C}_{5} \mathrm{H}_{3} \mathrm{~N}\right)_{n} \mathrm{CR}=\mathrm{NAr}(n=3,4,5 ; \mathrm{Ar}=2,6$-substituted aryl group; $\mathrm{R}=\mathrm{H}$ or hydrocarbyl), and have termed this family of ligands as oligopyridylimines (Fig. 1). ${ }^{5}$ It was envisaged that the steric attributes of these ligands would to some extent inhibit multi-stranded helicate formation and allow access to well-defined polymetallic complexes of the form [(oligopyridylimine) $\mathrm{M}_{x} \mathrm{X}_{y}$ ] ( $\mathrm{X}=$ anionic monodentate ligand) that could be amenable to further functionalisation at the metal centres and/or for catalytic applications.

Herein we report our efforts at developing the coordination chemistry of the potentially pentadentate $(n=3)$ member of

a Department of Chemistry, University of Leicester, University Road, Leicester,UKLE17RH.E-mail: gas8@leicester.ac.uk

${ }^{b}$ Department of Biochemistry, University of Leicester, University Road, Leicester, UK LE1 $7 R H$

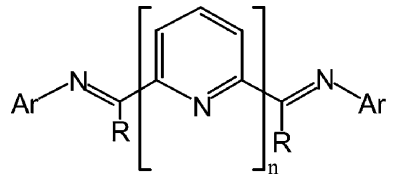

Fig. 1 Oligopyridylimines ( $\mathrm{R}=\mathrm{H}$ or hydrocarbyl, $\mathrm{Ar}=$ aryl $)$.

the family, bis(imino)terpyridine (Lx). To the knowledge of the authors, $\mathbf{L} \boldsymbol{x}$ has received scarcely any attention as a supporting ligand for binding to transition metals. ${ }^{6}$ Specifically, we focus on the reactivity of $6,6^{\prime \prime}-\left\{\left(2,6-i-\mathrm{Pr}_{2} \mathrm{C}_{6} \mathrm{H}_{3}\right) \mathrm{N}=\mathrm{CR}\right\}_{2}-2,2^{\prime}: 6^{\prime}, 2^{\prime \prime}-\mathrm{C}_{15} \mathrm{H}_{9} \mathrm{~N}_{3}$ $(\mathbf{L} \boldsymbol{x}=\mathbf{L} 1 \mathrm{R}=\mathrm{H} ; \mathbf{L} \boldsymbol{x}=\mathbf{L} 2 \mathrm{R}=\mathrm{Me})$ towards divalent metal halides of iron, nickel and zinc and pay particular attention to the effect of the imino-carbon substituent $\mathrm{R}$ on the nuclearity of the product. Furthermore, DFT calculations are used to support and complement the synthetic work.

\section{Results and discussion}

\section{(a) Syntheses of the ligands}

The ligands $6,6^{\prime \prime}-\left\{\left(2,6-i-\mathrm{Pr}_{2} \mathrm{C}_{6} \mathrm{H}_{3}\right) \mathrm{N}=\mathrm{CR}\right\}_{2}-2,2^{\prime}: 6^{\prime}, 2^{\prime \prime}-\mathrm{C}_{15} \mathrm{H}_{9} \mathrm{~N}_{3}$ ( $\mathrm{R}=\mathrm{H} \mathrm{L1}, \mathrm{R}=\mathrm{Me} \mathbf{L 2}$ ) were synthesised in good yield by the acid catalysed condensation reaction of $6,6^{\prime \prime}$-bis-formyl-2, $2^{\prime}: 6^{\prime}, 2^{\prime \prime}$ terpyridine ${ }^{5,7}$ and $6,6^{\prime \prime}$-bis-acetyl-2,2' $: 6^{\prime}, 2^{\prime \prime}$-terpyridine ${ }^{5}$ with two equivalents of 2,6-diisopropylaniline in ethanol, respectively (Scheme 1). Alternatively, L2 can be prepared by carrying out 


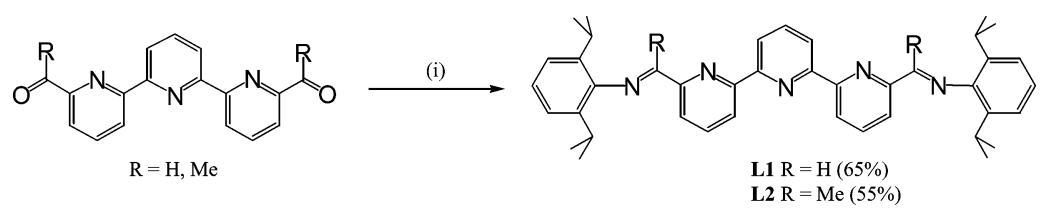

Scheme 1 Reagents and conditions: 2 eq. 2,6-i- $-\mathrm{Pr}_{2} \mathrm{C}_{6} \mathrm{H}_{3} \mathrm{NH}_{2}$, EtOH, cat. $\mathrm{H}^{+}$, heat.

Table 1 Selected bond distances $(\AA)$ and angles $\left(^{\circ}\right)$ for $\mathbf{L 2}$

\begin{tabular}{llll}
\hline $\mathrm{C}(13)-\mathrm{N}(1)$ & $1.284(6)$ & $\mathrm{C}(18)-\mathrm{C}(19)$ & $1.506(6)$ \\
$\mathrm{C}(29)-\mathrm{N}(5)$ & $1.255(6)$ & $\mathrm{C}(23)-\mathrm{C}(24)$ & $1.458(7)$ \\
$\mathrm{C}(29)-\mathrm{N}(5)-\mathrm{C}(30)$ & $119.8(4)$ & & \\
\hline
\end{tabular}

the reaction in neat 2,6-diisopropylaniline at elevated temperature over short time periods. ${ }^{5}$ Both ligands have been characterised by IR, ${ }^{1} \mathrm{H}$ and ${ }^{13} \mathrm{C}$ NMR spectroscopy along with ES mass spectrometry (see Experimental section). L2 has also been the subject of a single-crystal X-ray diffraction study.

Pale yellow crystals of $\mathbf{L} 2$ suitable for the X-ray determination were grown by the slow evaporation of a dichloromethane solution containing the compound. A view of $\mathbf{L} 2$ is shown in Fig. 2; selected bond distances and angles are listed in Table 1. The structure of L2 consists of three 2,6-linked pyridine rings with the imino groups occupying the ends of the oligopyridylimine chain. The nitrogen atoms of the pyridine groups adopt a mutually transoid conformation which is also extended to the terminal imine groups in a manner reminiscent of that found in 2,6-oligopyridines. ${ }^{1,8} \mathrm{~A}$ slight twist [torsion angles: $\mathrm{N}(1)-\mathrm{C}(13)-\mathrm{C}(14)-\mathrm{N}(2) 1.8^{\circ} ; \mathrm{N}(2)-\mathrm{C}(18)-\mathrm{C}(19)-$ $\mathrm{N}(3) 6.9^{\circ} ; \mathrm{N}(3)-\mathrm{C}(23)-\mathrm{C}(24)-\mathrm{N}(4) 3.4^{\circ} ; \mathrm{N}(4)-\mathrm{C}(28)-\mathrm{C}(29)-\mathrm{N}(5)$ $3.5^{\circ}$ ] from planarity is displayed throughout the imine-pyridine backbone as has been observed for L1. ${ }^{5}$ The 2,6-diisopropyl substituents on the terminal aryl groups sit above and below the planes of the nearest pyridine units within the chain. The N(1)$\mathrm{C}(13)$ and $\mathrm{N}(5)-\mathrm{C}(29)$ bond lengths of 1.284(6) and 1.255(6) $\AA$ are consistent with their being double bond character. The IR spectra of $\mathbf{L} 1$ and $\mathbf{L} 2$ confirm the presence of the imine with $v(\mathrm{C}=\mathrm{N})$ bands at $c a .1645 \mathrm{~cm}^{-1}$ which is supported by the ${ }^{13} \mathrm{C}$ NMR spectra which show peaks at $\delta 163.5(\mathbf{L 1})$ and $\delta 166.1$ (L2) corresponding to the imino carbon atoms.

\section{(b) Complexation reactions}

(i) Reaction of $\mathbf{M X}_{2}$ with L1. The reaction of $\mathbf{L 1}$ with one equivalent of $\mathrm{MX}_{2}\left[\mathrm{MX}_{2}=\mathrm{FeCl}_{2},(\mathrm{DME}) \mathrm{NiBr}_{2}, \mathrm{ZnCl}_{2}\right]$ in $n$ butanol at $110{ }^{\circ} \mathrm{C}$ gave complexes $\left[(\mathbf{L 1}) \mathrm{MX}_{2}\right](\mathrm{M}=\mathrm{Fe}, \mathrm{X}=\mathrm{Cl}$ 1a; $\mathrm{M}=\mathrm{Ni}, \mathrm{X}=\mathrm{Br} \mathbf{1 b} ; \mathrm{M}=\mathrm{Zn}, \mathrm{X}=\mathrm{Cl} \mathbf{1 c}$ ) in high yield (Scheme 2). No evidence for bimetallic products was apparent on addition of two equivalents or greater of $\mathrm{MX}_{2}$ or after stirring for longer periods. All products have been characterised by microanalysis, FAB mass spectrometry, IR spectroscopy and, in the cases of $\mathbf{1 a}$ and $\mathbf{1 b}$, by magnetic measurements and $\mathbf{1 c}$ by ${ }^{1} \mathrm{H}$ NMR spectroscopy (see Table 2 and Experimental section). In addition, crystals of $\mathbf{1 a}, \mathbf{1 b}$ and $\mathbf{1 c}$ have been subjected to singlecrystal X-ray diffraction studies.

Crystals of 1a, $\mathbf{1 b}$ and $\mathbf{1 c}$ suitable for the X-ray determinations were grown by slow cooling of hot acetonitrile solutions containing the complexes. The structures of $\mathbf{1 a}, \mathbf{1 b}$ and $\mathbf{1 c}$ are similar and only 1a will be discussed in any detail. A view of 1a is depicted in Fig. 3; selected bond distances and angles for 1a, $\mathbf{1 b}$ and $\mathbf{1 c}$ are listed in Table 3. The molecular structure of 1a depicts a single iron centre bound by $\mathbf{L 1}$ and two terminal chloride ligands. The metal centre occupies the tridentate terpyridine cavity with the two imine groups pendant and exo to the coordinated terpyridine moiety. The geometry at the metal centre can be best described as distorted trigonal bipyramidal with $\mathrm{N}(2)$ and $\mathrm{N}(2 \mathrm{~A})$ defining the axial sites $\left[\mathrm{N}(2)-\mathrm{Fe}(1)-\mathrm{N}(2 \mathrm{~A}) 150.8(3)^{\circ}\right]$ and $\mathrm{N}(3), \mathrm{Cl}(1)$ and $\mathrm{Cl}(1 \mathrm{~A})$ the equatorial ones [N(3)- $\mathrm{Fe}(1)-\mathrm{Cl}(1) 120.99(5) ; \mathrm{Cl}(1)-\mathrm{Fe}(1)-\mathrm{Cl}(1 \mathrm{~A})$ $\left.118.03(9)^{\circ}\right]$. The complex has molecular $C_{2}$ symmetry about an axis containing the metal, the pyridyl-N(3) and $\mathrm{C}(21)$ atoms. The central $\mathrm{M}-\mathrm{N}_{\text {pyridyl }}$ distance [2.073(6) $\AA$ ] is noticeably less than the $\mathrm{M}-\mathrm{N}(2)_{\text {pyridyl }}$ and $\mathrm{M}-\mathrm{N}(2 \mathrm{~A})_{\text {pyridyl }}$ bond lengths [2.234(5) $\AA$ ], probably as a consequence of satisfying the tridentate chelating constraint of the ligand and that it occupies a equatorial site within the trigonal bipyramid. The $\mathrm{C}=\mathrm{N}$ bond distance $[1.283(8) \AA]$ is similar to that found in $\mathbf{L} 2$ [av. $1.258 \AA$ ] .

The FAB mass spectra for $\mathbf{1 a - c}$ show fragmentation peaks corresponding to the loss of one halide group from the corresponding molecular ion peak. The IR spectra for $\mathbf{1 a}-\mathbf{c}$ display $v(\mathrm{C}=\mathrm{N})$ bands at $c a .1635 \mathrm{~cm}^{-1}$ and in a similar region to that for free $\mathbf{L 1}$, supporting the pendant nature of the imino groups. Complexes $\mathbf{1 a}$ and $\mathbf{1 b}$ are paramagnetic and display magnetic moments of 5.3 and $2.8 \mu_{\mathrm{B}}$ (Evans Balance at ambient temperature) which are consistent with high spin configurations possessing four and two unpaired electrons, respectively. In contrast, complex $\mathbf{1 c}$ is

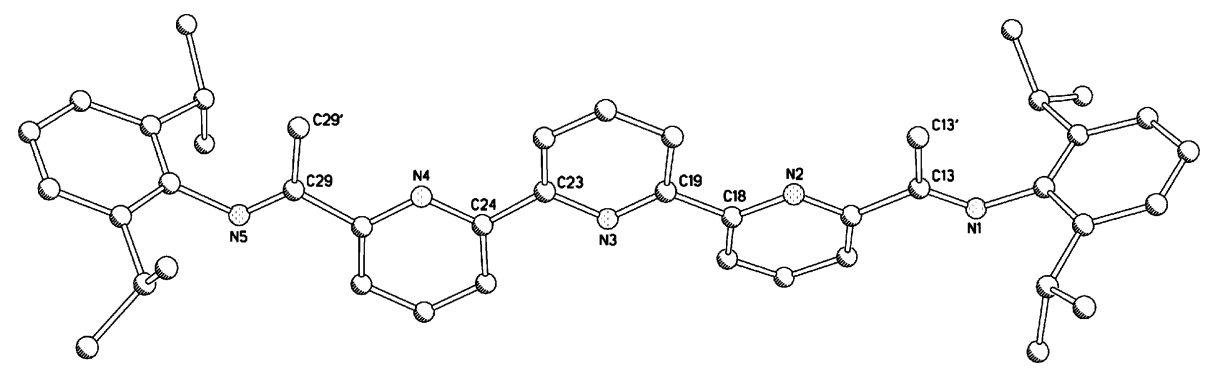

Fig. 2 Molecular structure of $\mathbf{L} 2$ including the atom numbering scheme. 


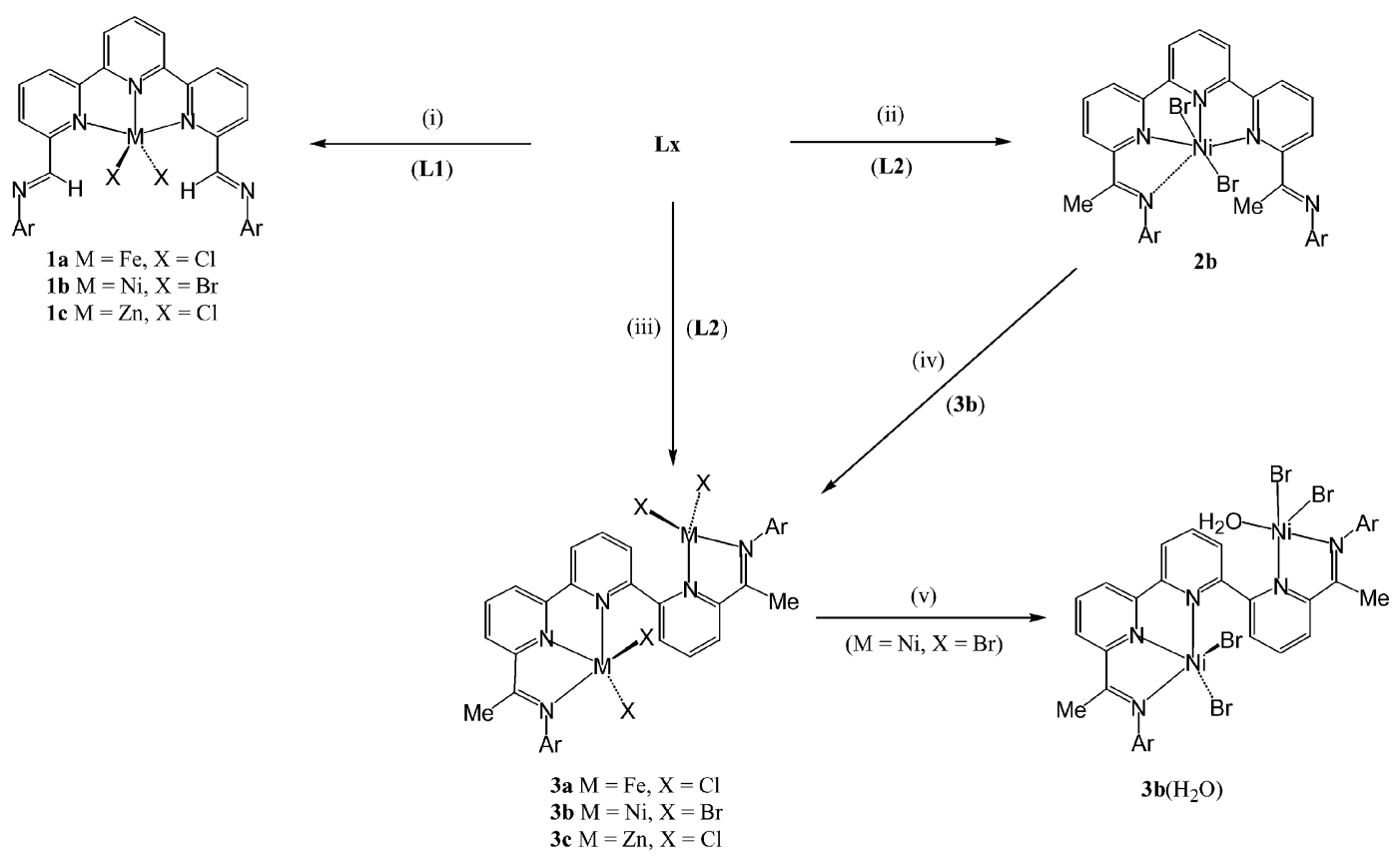

Scheme 2 Reagents and conditions: (i) 1 eq. or xs. $\mathrm{MX}_{2}\left[\mathrm{MX}_{2}=\mathrm{FeCl}_{2},(\mathrm{DME}) \mathrm{NiBr}_{2}, \mathrm{ZnCl}_{2}\right], n$ - $\mathrm{BuOH}, 110{ }^{\circ} \mathrm{C}$; (ii) 1 eq. (DME)NiBr 2 , CH $\mathrm{Cl}_{2}, \mathrm{RT}$; (iii) 2 eq. $\mathrm{MX}_{2}\left[\mathrm{MX}_{2}=\mathrm{FeCl}_{2}\right.$, (DME) $\left.\mathrm{NiBr}_{2}, \mathrm{ZnCl}_{2}\right], n$ - $\mathrm{BuOH}, 110^{\circ} \mathrm{C}$; (iv) 1 eq. (DME) $\mathrm{NiBr}_{2}, n$ - $\mathrm{BuOH}, 110^{\circ} \mathrm{C}$; (v) $\mathrm{CHCl} 3 / \mathrm{H}_{2} \mathrm{O}, \mathrm{RT}\left(\mathrm{Ar}_{2}=2,6-i\right.$ - $\left.\mathrm{Pr}_{2} \mathrm{C}_{6} \mathrm{H}_{3}\right)$.

Table 2 Characterisation data for the new complexes 1-3

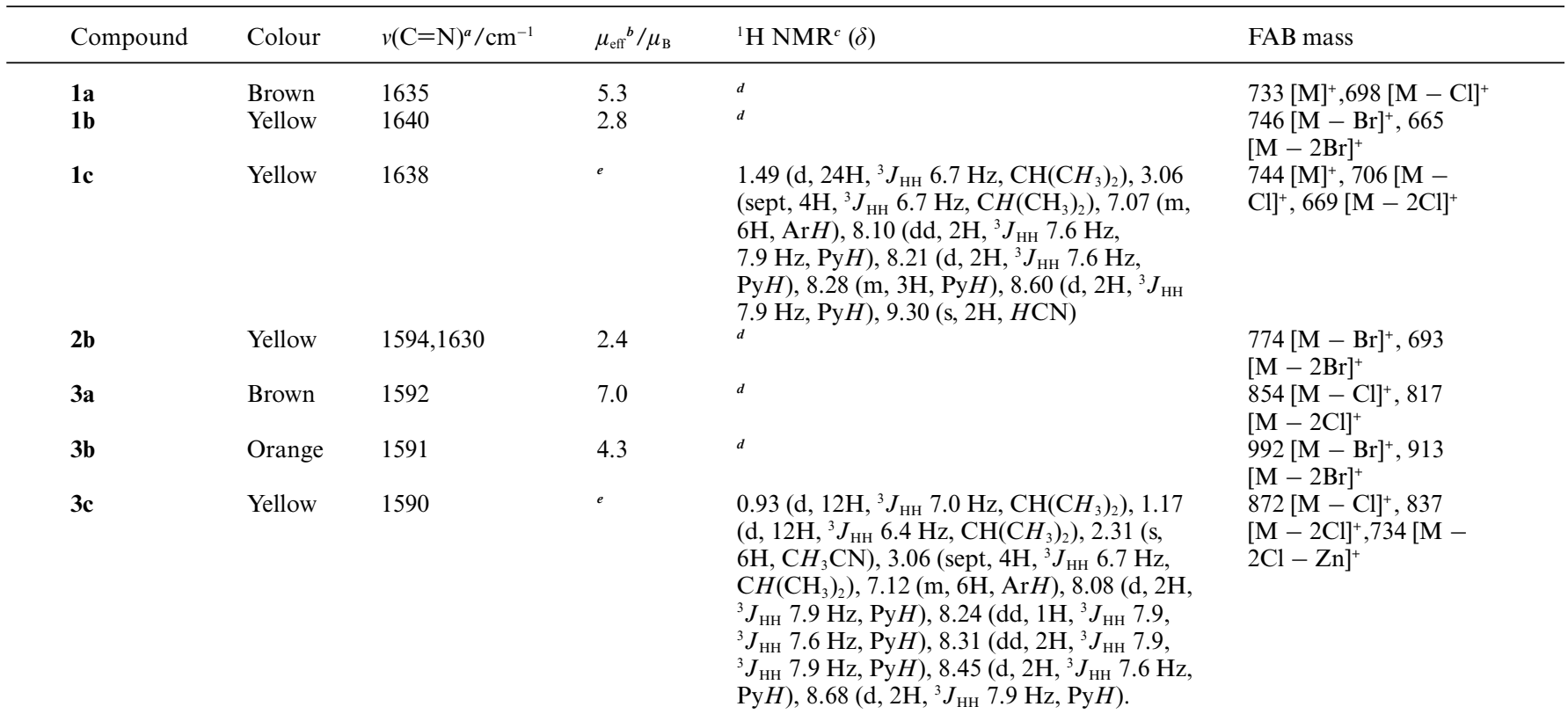

${ }^{a}$ Recorded on a Perkin-Elmer Spectrum One FT-IR spectrometer on solid samples. ${ }^{b}$ Recorded on an Evans Balance at room temperature. ${ }^{c}$ Recorded in $\mathrm{CDCl}_{3}$ solution at room temperature. ${ }^{d}$ Broad paramagnetically shifted resonances. ${ }^{e}$ Diamagnetic.

diamagnetic and exhibits a ${ }^{1} \mathrm{H}$ NMR spectrum (in $\mathrm{CDCl}_{3}$ at ambient temperature) that is consistent with the molecular $C_{2}$ symmetry observed in the solid state with five signals for the pyridyl protons. In comparison with L1, the signals are slightly shifted with, for example, the singlet for the $\mathrm{CH}=\mathrm{N}$ protons in L1 ( $\delta$ 8.36) being shifted by $c a .1$ ppm downfield in 1c $(\delta 9.30)$. The ${ }^{1} \mathrm{H}$ NMR spectra for paramagnetic $\mathbf{1 a}$ and $\mathbf{1 b}$ were broad and uninformative. (ii) Reaction of $\mathbf{M X} \mathbf{X}_{2}$ with $\mathbf{L 2}$. The reaction of $\mathbf{L 2}$ with two equivalents of $\mathrm{MX}_{2}\left[\mathrm{MX}_{2}=\mathrm{FeCl}_{2},(\mathrm{DME}) \mathrm{NiBr}_{2}, \mathrm{ZnCl}_{2}\right]$ in $n$ butanol at elevated temperatures gave complexes $\left[(\mathbf{L} 2) \mathrm{M}_{2} \mathrm{X}_{4}\right](\mathrm{M}=$ $\mathrm{Fe}, \mathrm{X}=\mathrm{Cl}$ 3a; $\mathrm{M}=\mathrm{Ni}, \mathrm{X}=\mathrm{Br} \mathbf{3 b} ; \mathrm{M}=\mathrm{Zn}, \mathrm{X}=\mathrm{Cl}$ 3c) in high yield (Scheme 2). No evidence for monometallic products was apparent under these experimental conditions nor when one equivalent of $\mathrm{MX}_{2}$ was employed. All products have been characterised by FAB mass spectrometry, IR spectroscopy and, in the cases of $\mathbf{3} \mathbf{a}$ and $\mathbf{3 b}$, 
Table 3 Selected bond distances $(\AA)$ and angles $\left({ }^{\circ}\right)$ for $\mathbf{1 a}, \mathbf{1 b}$ and $\mathbf{1 c}$

\begin{tabular}{llll}
\hline & $\mathbf{1 a}(\mathrm{M}=\mathrm{Fe}, \mathrm{X}=\mathrm{Cl})$ & $\mathbf{1 b}(\mathrm{M}=\mathrm{Ni}, \mathrm{X}=\mathrm{Br})$ & $\mathbf{1 c}(\mathrm{M}=\mathrm{Zn}, \mathrm{X}=\mathrm{Cl})$ \\
\hline $\mathrm{M}(1)-\mathrm{N}(2)$ & $2.234(5)$ & $2.110(6)$ & $2.242(7)$ \\
$\mathrm{M}(1)-\mathrm{N}(3)$ & $2.073(6)$ & $1.982(6)$ & $2.036(8)$ \\
$\mathrm{M}(1)-\mathrm{N}(2 \mathrm{~A})$ & $2.234(5)$ & $2.110(6)$ & $2.242(7)$ \\
$\mathrm{M}(1)-\mathrm{X}(1)$ & $2.2889(17)$ & $2.3919(9)$ & $2.247(2)$ \\
$\mathrm{M}(1)-\mathrm{X}(1 \mathrm{~A})$ & $2.2889(17)$ & $2.3919(9)$ & $2.247(2)$ \\
$\mathrm{C}(13)-\mathrm{N}(1)$ & $1.283(8)$ & $1.251(9)$ & $1.278(12)$ \\
& & & $76.16(18)$ \\
$\mathrm{N}(2)-\mathrm{M}(1)-\mathrm{N}(3)$ & $75.42(13)$ & $78.33(13)$ & $152.3(4)$ \\
$\mathrm{N}(2)-\mathrm{M}(1)-\mathrm{N}(2 \mathrm{~A})$ & $150.8(3)$ & $156.7(3)$ & $119.10(14)$ \\
$\mathrm{X}(1)-\mathrm{M}(1)-\mathrm{X}(1 \mathrm{~A})$ & $118.03(9)$ & $93.71(18)$ \\
$\mathrm{X}(1)-\mathrm{M}(1)-\mathrm{N}(2)$ & $93.50(13)$ & $115.76(15)$ & $120.45(7)$ \\
$\mathrm{X}(1)-\mathrm{M}(1)-\mathrm{N}(3)$ & $120.99(5)$ & $98.15(15)$ & $100.24(19)$
\end{tabular}

Atoms with suffix A are generated by symmetry.

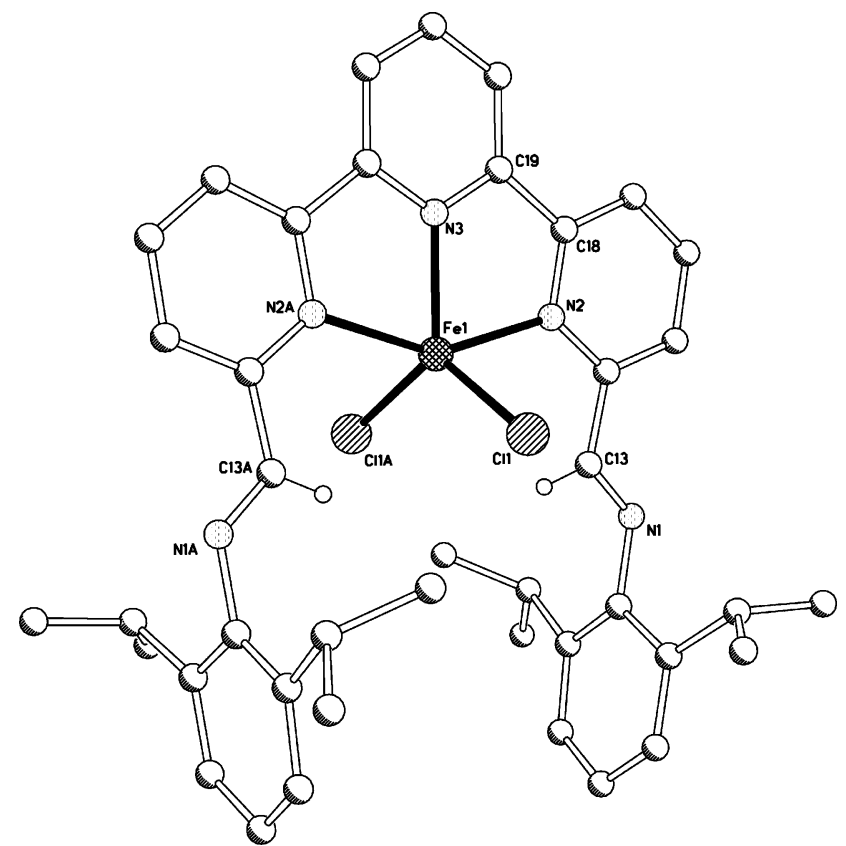

Fig. 3 Molecular structure of 1a; the atoms labelled with an additional A are generated by symmetry $(1-x,-y, z)$. All hydrogen atoms, apart from $\mathrm{H} 13$, have been omitted for clarity.

by magnetic measurements and for $3 \mathbf{c}$ by ${ }^{1} \mathrm{H}$ NMR spectroscopy (see Table 2 and Experimental section). In addition, crystals of $\mathbf{3 a}$ and $\mathbf{3 c}$ have been the subject of single-crystal X-ray diffraction studies.

Crystals of 3a and $\mathbf{3} \mathbf{c}$ were grown by slow cooling of hot acetonitrile solutions of the corresponding complexes. The structures of 3a and $\mathbf{3 c}$ are essentially the same and will be discussed together. A view of $\mathbf{3 c}$ is depicted in Fig. 4; selected bond distances and angles are listed for both $\mathbf{3 a}$ and $\mathbf{3} \mathbf{c}$ in Table 4 . The molecular structures reveal bimetallic complexes in which the two metal centres are supported on the same $\mathbf{L} 2$ ligand frame and each bound terminally by two chloride ligands. One of the metal centres [M(2)] occupies a bidentate pyridylimine pocket while the other [M(1)] a tridentate dipyridylimine cavity so as to generate a tetrahedral geometry at M(2) and a distorted square pyramidal geometry at M(1). Within the ligand frame the pyridylimine and dipyridylimine moieties are both nearly planar with each of the planes being disposed almost orthogonally to one another [torsion angles: $\mathrm{N}(3)-\mathrm{C}(18)-$ $\mathrm{C}(19)-\mathrm{N}(4) 91.5^{\circ}$ (3a), $90.6^{\circ}$ (3c)]. For M(1) the two M(1)-Cl bond lengths are a essentially equivalent [3a 2.273(2) vs. 2.281(2) $\AA$; 3c 2.2254(12) vs. 2.2367(12) $\AA$ ], while the $\mathrm{M}(1)-\mathrm{N}$ distances vary with $\mathrm{M}(1)-\mathrm{N}(2)$ [3a 2.061(6) $\AA$; 3c 2.064(3) $\mathrm{A}$ ] being shorter than the

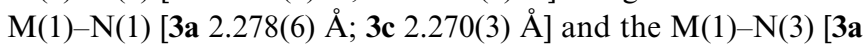

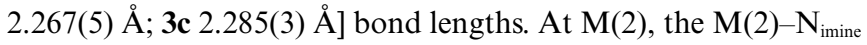
distance is similar to the $\mathrm{M}(2)-\mathrm{N}_{\text {pyridyl }}$ bond length [3a 2.109(5) vs. 2.102(6) $\AA$; 3c 2.071(3) vs. 2.056(3) $\AA$ ]. There is no apparent delocalisation of the imino double bond into the adjacent pyridyl group.

Attempted crystallisation of $\mathbf{3 b}$ using the conditions applied for 3a and 3c proved unsuccessful. However, by prolonged standing in chloroform adventitious reaction with water occurs to give $\left[(\mathbf{L 2}) \mathrm{Ni}_{2} \mathrm{Br}_{4}\left(\mathrm{OH}_{2}\right)\right]\left[3 \mathbf{b}\left(\mathrm{H}_{2} \mathrm{O}\right)\right]$ as orange crystals (Scheme 2). The dataset obtained for the single-crystal X-ray determination was, unfortunately, of poor quality. Nevertheless, the structure was unequivocal in revealing a bimetallic species displaying structural features similar to that observed in $\mathbf{3 a}$ and $\mathbf{3 c}$ (vide supra) but with one molecule of water additionally bound to the nickel centre [Ni(2)] occupying the bidentate cavity in L2. For comparison, Table 4 also contains the corresponding bond lengths and angles for $3 \mathbf{b}\left(\mathrm{H}_{2} \mathrm{O}\right)$.

The FAB mass spectra for $\mathbf{3 a - c}$ show fragmentation peaks corresponding to the loss of one or two halide groups from the corresponding molecular ion peak. In the IR spectra for $\mathbf{3 a}-\mathbf{c}$, the $v\left(\mathrm{C}=\mathrm{N}\right.$ ) bands are seen at $c a .1590 \mathrm{~cm}^{-1}$ (in both solid and solution state) and shifted to a lower wavenumber by $c a .52 \mathrm{~cm}^{-1}$ in comparison with the free ligand $\mathbf{L 2}$; supporting coordination of both imine groups. Complexes $\mathbf{3} \mathbf{a}$ and $\mathbf{3 b}$ are paramagnetic and display magnetic moments of $7.0 \mu_{\mathrm{B}}$ and $4.3 \mu_{\mathrm{B}}$ (Evans Balance at ambient temperature) which are consistent with non-spin coupled $\mathrm{Fe}(\mathrm{II})(S=2)-\mathrm{Fe}(\mathrm{II})(S=2)$ and $\mathrm{Ni}(\mathrm{II})(S=1)-\mathrm{Ni}(\mathrm{II})(S=1)$ systems (using $\mu^{2}=\sum \mu_{i}{ }^{2}$, where $\mu_{i}$ is the magnetic moment of the individual metal centres). ${ }^{9}$

The ${ }^{1} \mathrm{H}$ NMR spectrum of $\mathbf{3 c}$ in $\mathrm{CDCl}_{3}$ (at ambient temperature) indicates that the molecule has average $C_{2}$ symmetry in solution with only five resonances for the pyridyl hydrogen atoms occurring at $\delta 8.08,8.24,8.31,8.45$ and 8.68 . In addition, there is only one resonance for the methyl protons on the imine groups. Attempts to lower the symmetry by recording the spectrum at lower 
Table 4 Selected bond distances $(\AA)$ and angles $\left({ }^{\circ}\right)$ for $\mathbf{3 a}, \mathbf{3 b}\left(\mathrm{H}_{2} \mathrm{O}\right)$ and $\mathbf{3 c}$

\begin{tabular}{|c|c|c|c|}
\hline & 3a $(\mathrm{M}=\mathrm{Fe}, \mathrm{X}=\mathrm{Cl})$ & $3 \mathbf{b}\left(\mathrm{H}_{2} \mathrm{O}\right)(\mathrm{M}=\mathrm{Ni}, \mathrm{X}=\mathrm{Br})$ & $3 \mathbf{c}(\mathrm{M}=\mathrm{Zn}, \mathrm{X}=\mathrm{Cl})$ \\
\hline $\mathrm{M}(1)-\mathrm{N}(1)$ & $2.278(6)$ & $2.157(17)$ & $2.270(3)$ \\
\hline $\mathrm{M}(1)-\mathrm{N}(2)$ & $2.061(6)$ & $1.933(17)$ & $2.064(3)$ \\
\hline $\mathrm{M}(1)-\mathrm{X}(1)$ & $2.273(2)$ & $2.421(4)$ & $2.2254(12)$ \\
\hline$M(1)-X(2)$ & $2.281(2)$ & $2.394(4)$ & $2.2367(12)$ \\
\hline $\mathrm{M}(2)-\mathrm{N}(4)$ & $2.102(6)$ & $2.079(17)$ & $2.056(3)$ \\
\hline $\mathrm{M}(2)-\mathrm{N}(5)$ & $2.109(5)$ & $2.036(17)$ & $2.071(3)$ \\
\hline $\mathrm{M}(2)-\mathrm{X}(4)$ & $2.237(2)$ & $2.427(4)$ & $2.2212(13)$ \\
\hline $\mathrm{C}(7)-\mathrm{N}(1)$ & $1.269(9)$ & $1.26(3)$ & $1.289(5)$ \\
\hline $\mathrm{C}(24)-\mathrm{N}(5)$ & $1.268(8)$ & $1.38(2)$ & $1.274(5)$ \\
\hline $\mathrm{N}(1)-\mathrm{M}(1)-\mathrm{N}(2)$ & $73.9(2)$ & $78.0(7)$ & $74.47(13)$ \\
\hline $\mathrm{N}(1)-\mathrm{M}(1)-\mathrm{N}(3)$ & $149.4(2)$ & $154.0(6)$ & $149.61(12)$ \\
\hline $\mathrm{N}(4)-\mathrm{M}(2)-\mathrm{X}(3)$ & $119.75(18)$ & $172.3(5)$ & $119.86(10)$ \\
\hline $\mathrm{N}(4)-\mathrm{M}(2)-\mathrm{X}(4)$ & $103.73(17)$ & $89.3(5)$ & $104.53(10)$ \\
\hline $\mathrm{N}(4)-\mathrm{Ni}(2)-\mathrm{O}(1)_{\mathrm{H}_{2} \mathrm{O}}$ & - & $85.8(7)$ & - \\
\hline $\mathrm{X}(3)-\mathrm{M}(2)-\mathrm{X}(4)$ & $118.76(9)$ & $95.88(13)$ & $116.80(5)$ \\
\hline
\end{tabular}

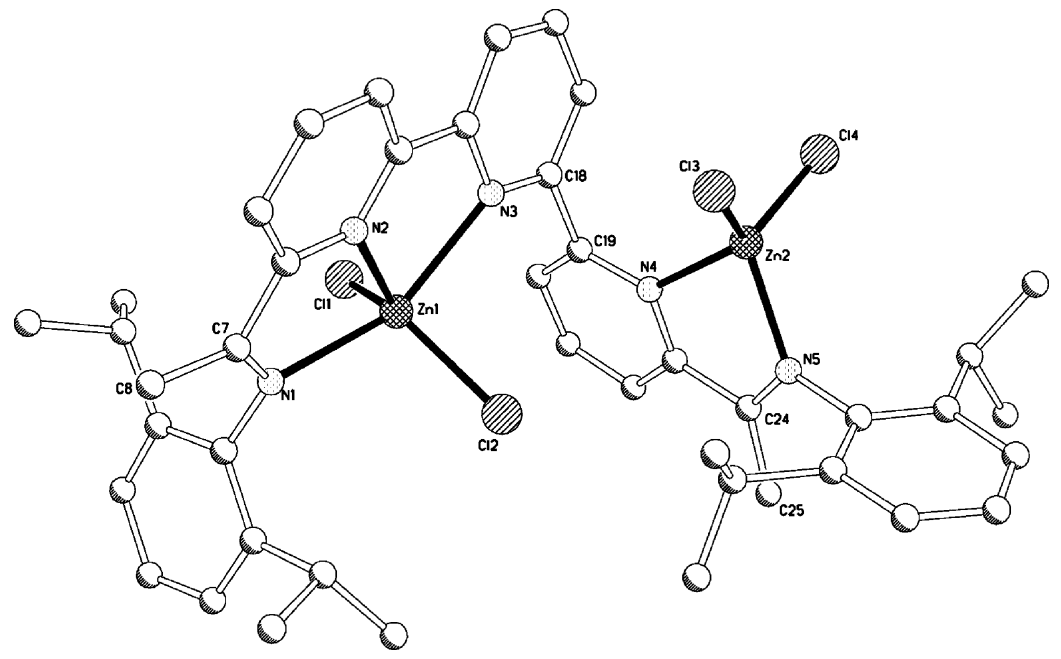

Fig. 4 Molecular structure of $3 \mathbf{c}$ including the atom numbering scheme. All hydrogen atoms have been omitted for clarity.

temperature were, however, hampered by solubility problems. Scheme 3 indicates a possible fluxional process that could be operating at room temperature in solution in which the central pyridine group could be flipping between metal centre coordination. An alternative explanation may be that the central pyridine nitrogen donor is not coordinated in solution.
With the intent of synthesising monometallic complexes bound by $\mathbf{L 2}$, the reaction with $\mathrm{MX}_{2}$ was attempted under milder conditions. Thus, when a cooled dichloromethane solution of (DME) $\mathrm{NiBr}_{2}$ is treated with one equivalent of $\mathbf{L} \mathbf{2}$ and left to stir overnight at room temperature, the yellow mononuclear complex $\left[(\mathbf{L 2}) \mathrm{NiBr}_{2}\right]$ (2b) can be obtained in good yield. Attempted
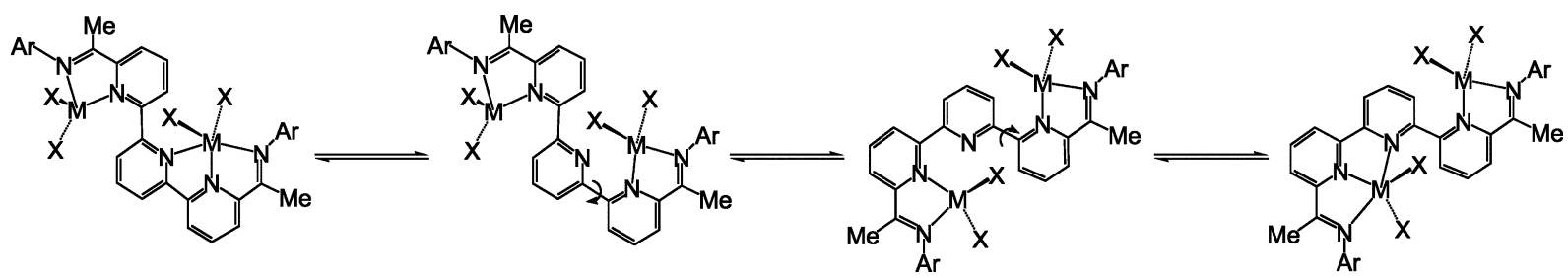

Scheme 3 Possible dynamic process operating for 3. 
isolation of the mononuclear zinc analogue of $\mathbf{2 b},\left[(\mathbf{L} 2) \mathrm{ZnCl}_{2}\right](\mathbf{2 c})$, under the same reaction conditions as employed above, proved problematic with $\mathbf{3 c}$ and $\mathbf{L} \mathbf{2}$ being the main species identifiable in the ${ }^{1} \mathrm{H}$ NMR spectrum. Complex $\mathbf{2 b}$ was characterised by FAB mass spectrometry, IR spectroscopy and by magnetic measurements (see Table 2 and Experimental section). In addition, a crystal of $\mathbf{2 b}$ has been the subject of a single-crystal X-ray diffraction study.

Crystals of $\mathbf{2 b}$ suitable for the X-ray determination were grown by prolonged standing in chloroform. A view of $\mathbf{2 b}$ is shown in Fig. 5; selected bond distances and angles are listed in Table 5. The molecular structure consists of a single nickel atom bound by both $\mathbf{L} 2$ and two terminal bromide ligands. As with its L1-containing counterpart, $\mathbf{1 b}$, the metal centre occupies the terpyridine cavity of the bis(imino)terpyridine ligand. In this case, however, only one of the imino groups is exo while the other is endo and forms a partial interaction with the nickel centre $[\mathrm{Ni}(1) \cdots \mathrm{N}(1) 2.537(2) \AA]$. The effect of the interaction in comparison with $\mathbf{1 b}$ is two-fold. Firstly, an increase in the $\mathrm{Br}-\mathrm{Ni}-\mathrm{Br}$ angle from $129.51(6)^{\circ}$ in $\mathbf{1 b}$ to $172.84(2)^{\circ}$ in $\mathbf{2 b}$ occurs so that the nickel assumes a more octahedral geometry in $\mathbf{3 b}$. Secondly, the occupation of terpyridine cavity is more uneven with the nickel centre more disposed towards

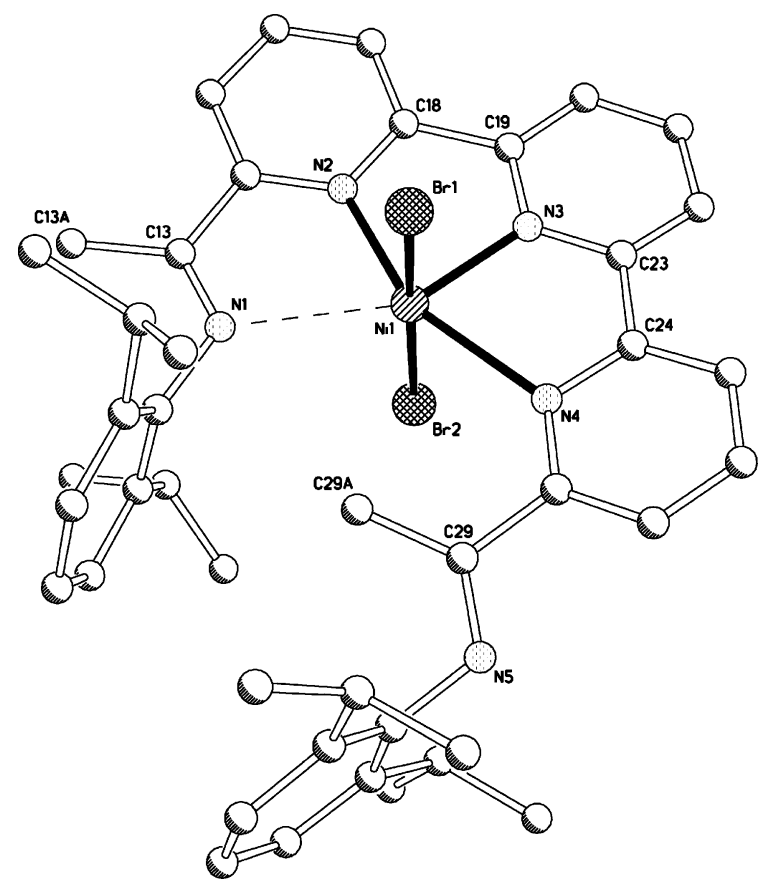

Fig. 5 Molecular structure of $\mathbf{2 b}$ including the atom numbering scheme. All hydrogen atoms have been omitted for clarity.

Table 5 Selected bond distances $(\AA)$ and angles $\left({ }^{\circ}\right)$ for $\mathbf{2 b}$

\begin{tabular}{lllr}
\hline $\mathrm{Ni}(1) \cdots \mathrm{N}(1)$ & $2.537(2)$ & $\mathrm{Ni}(1)-\mathrm{Br}(1)$ & $2.4827(7)$ \\
$\mathrm{Ni}(1)-\mathrm{N}(2)$ & $2.040(2)$ & $\mathrm{Ni}(1)-\mathrm{Br}(2)$ & $2.4780(7)$ \\
$\mathrm{Ni}(1)-\mathrm{N}(3)$ & $1.982(2)$ & $\mathrm{N}(1)-\mathrm{C}(13)$ & $1.269(4)$ \\
$\mathrm{Ni}(1)-\mathrm{N}(4)$ & $2.316(2)$ & $\mathrm{N}(5)-\mathrm{C}(29)$ & $1.277(4)$ \\
& & & \\
$\mathrm{N}(2)-\mathrm{Ni}(1)-\mathrm{N}(3)$ & $79.76(10)$ & $\mathrm{N}(2)-\mathrm{Ni}(1)-\mathrm{Br}(1)$ & $93.04(7)$ \\
$\mathrm{N}(3)-\mathrm{Ni}(1)-\mathrm{Br}(2)$ & $92.49(7)$ & $\mathrm{N}(2)-\mathrm{Ni}(1)-\mathrm{N}(4)$ & $156.26(9)$ \\
$\mathrm{N}(3)-\mathrm{Ni}(1)-\mathrm{N}(4)$ & $76.51(9)$ & $\mathrm{N}(4)-\mathrm{Ni}(1)-\mathrm{Br}(1)$ & $86.80(6)$ \\
$\mathrm{N}(3)-\mathrm{Ni}(1)-\mathrm{Br}(1)$ & $90.81(7)$ & $\mathrm{N}(4)-\mathrm{Ni}(1)-\mathrm{Br}(2)$ & $87.78(6)$ \\
$\mathrm{N}(2)-\mathrm{Ni}(1)-\mathrm{Br}(2)$ & $93.80(7)$ & $\mathrm{Br}(2)-\mathrm{Ni}(1)-\mathrm{Br}(1)$ & $172.84(2)$ \\
\hline
\end{tabular}

one of the exterior pyridine units than the other $[\mathrm{Ni}(1)-\mathrm{N}(2)$ 2.040(2) vs. $\mathrm{Ni}(1)-\mathrm{N}(4)$ 2.316(2) $\AA$ ], while the central pyridine remains strongly bound [Ni(1)-N(3) 1.982(2) $\AA$ ]. The effect of partial coordination on the $\mathrm{C}-\mathrm{N}$ double bond length in the imine is minimal.

The FAB mass spectrum for $\mathbf{2 b}$ shows fragmentation peaks corresponding to the loss of one or two bromide groups from the molecular ion peak. In the IR spectra for $\mathbf{2 b}, v(\mathrm{C}=\mathrm{N})$ bands at 1594 and $1630 \mathrm{~cm}^{-1}$ support the presence of both bound and free imino groups, respectively. As with $\mathbf{1 b}, \mathbf{2 b}$ is paramagnetic exhibiting a magnetic moment of $2.4 \mu_{\mathrm{B}}$ (Evans Balance at ambient temperature) which is consistent with presence of two unpaired electrons.

Conversion of yellow $\mathbf{2 b}$ to orange $\mathbf{3 b}$ can be achieved in good yield by treating $\mathbf{2 b}$ with one equivalent of (DME) $\mathrm{NiBr}_{2}$ in $n$-butanol at $110{ }^{\circ} \mathrm{C}$ for $30 \mathrm{~min}$ (Scheme 2). Similarly, 2b could be converted to $\mathbf{3 b}$ on refluxing $\mathbf{2} \mathbf{b}$ with one equivalent of (DME) $\mathrm{NiBr}_{2}$ in dichloromethane for two days, these conditions also proving successful for the preparation of $\mathbf{3 b}$ directly from $\mathbf{L} 2$.

\subsection{Density functional theory calculations}

The capacity of $\mathbf{L} \boldsymbol{x}$, depending on the nature of the imino-carbon substituent, to have a selectivity for the number of metal(II) halide units it binds was unexpected. Although it could be argued that differences in electronic properties within the two ligand manifolds (e.g., donor capability of the nitrogen donors within $\mathbf{L} \boldsymbol{x}$ is expected to follow the order: pyridine $>$ ketimine $>$ aldimine ${ }^{10}$ ) should be influential, such a dramatic change in binding affinity was nevertheless surprising. Therefore, a theoretical study on the relative stability of mononuclear $\left[(\mathbf{L} 2) \mathrm{MX}_{2}\right]$ and $\left[(\mathbf{L} 1) \mathrm{MX}_{2}\right]$ was carried out in order to investigate in more detail the energetic properties of these systems. Specifically, density functional calculations have been performed on $\mathrm{ZnCl}_{2}$-containing complexes and is likely, given the similarity of the experimental results, to be representative of the other metal halide systems employed in this work.

For both $\mathbf{L 1}$ and L2, B3LYP calculations have been undertaken on mono-zinc dichloride species in conformations $\mathbf{1}_{\mathrm{L} x}$ and $\mathbf{2}_{\mathrm{L} x}$ (Fig. 6) which are based on the conformations adopted in structurally determined $\mathbf{1 c}$ and $\mathbf{2 b}$. In addition, hypothetical species $\mathbf{4}_{\mathrm{L} x}$ derived from the removal of one zinc dichloride unit from the bidentate pocket in bimetallic $\mathbf{3 c}$ are also studied. As 1c is the only monometallic $\mathrm{ZnCl}_{2}$ structure characterised by $\mathrm{X}$-ray diffraction, it was used to test our theoretical approach. For this configuration, theoretical $\left(\mathbf{1}_{\mathrm{L} 1}\right)$ and experimental (1c) structures are in good agreement with the discrepancies found being less than $0.07 \AA$ for the bond lengths and $10^{\circ}$ for the angles (see Tables 3 and 6 ). The coordinated terpyridine portion of the ligand remains planar with an out of plane displacement of 0.03 and $0.05 \AA$ for the theoretical and experimental structures, respectively [Fig. 7(ii)]. It is likely that any discrepancies can be attributed to the vacuum conditions of the calculations. Therefore, it was viewed that this initial study demonstrated that using the B3LYP functional with our basis set is viable for studying such large systems. To extend the investigation, we have applied this theoretical approach to mono-zinc complexes that have not been characterised crystallographically. 
Table 6 Selected calculated bond distances $(\AA)$ and angles $\left({ }^{\circ}\right)$ for $\left[(\mathbf{L 1}) \mathrm{ZnCl}_{2}\right]$ and $\left[(\mathbf{L 2}) \mathrm{ZnCl}_{2}\right]$ in types-1, $\mathbf{- 2}$ and $\mathbf{- 4}$ conformations

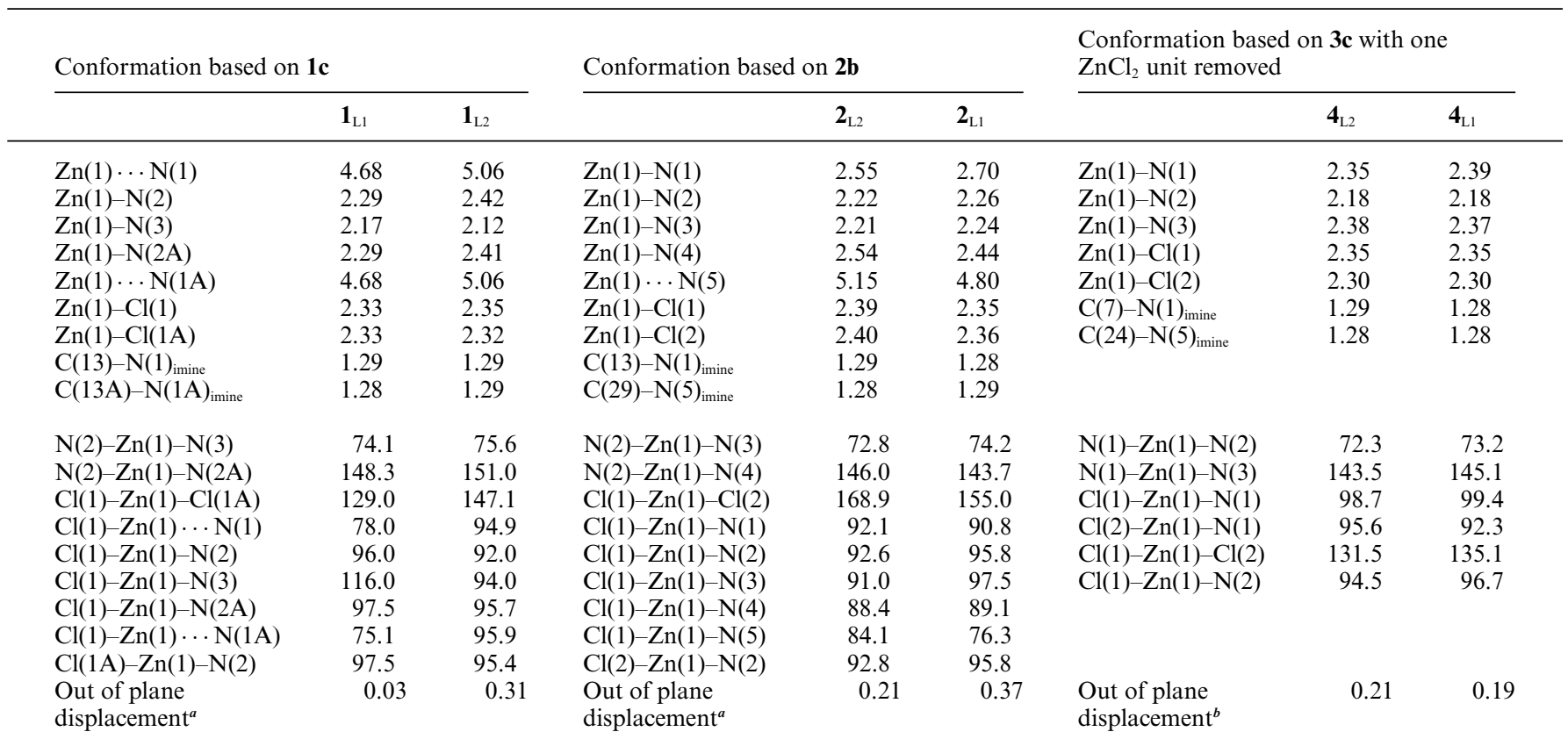

${ }^{a}$ Out of plane displacement of the eighteen atoms in the three pyridine moieties. ${ }^{b}$ Out of plane displacement of the fifteen atoms in the imino-bipyridine moiety.
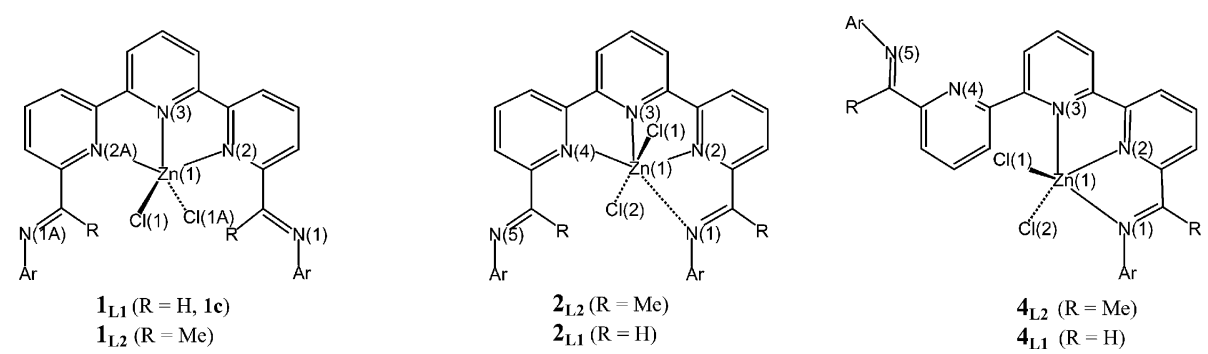

Fig. 6 Monometallic zinc conformations to be investigated by DFT including the atom numbering scheme $\left(\operatorname{Ar}=2,6-i-\mathrm{Pr}_{2} \mathrm{C}_{6} \mathrm{H}_{3}\right)$.

Firstly, $\mathbf{1}_{\mathrm{L} 2}$ has been optimised. The resulting structure exhibits a geometry substantially distorted when compared with its counterpart $\mathbf{1}_{\mathrm{L} 1}$ [Fig. 7(iii) vs. (ii)]. Inspection of the coordination sphere around zinc in $\mathbf{1}_{\mathrm{L} 2}$ indicates that $\mathrm{N} 2$ and $\mathrm{N} 2 \mathrm{~A}$ atoms lie further away from the metal centre $\left[\mathrm{Zn}(1)-\mathrm{N}(2) / \mathrm{N}(2 \mathrm{~A}) 2.42 \AA\left(\mathbf{1}_{\mathrm{L} 2}\right) v s\right.$. $\left.\mathrm{Zn}(1)-\mathrm{N}(2) / \mathrm{N}(2 \mathrm{~A}) 2.29 \AA\left(\mathbf{1}_{\mathrm{L} 1}\right)\right]$ implying that the chelating ability of $\mathbf{L 2}$ in this coordination mode is substantially reduced (Table 6). This observation is likely linked to the steric constraints imposed by the methyl units of the imino-carbon groups which are in close proximity in this conformation [Fig. 7(iii)]. The geometry around the metal is also altered in the fact that both chlorine atoms while equivalent in $\mathbf{1}_{\mathrm{L} 1}$ are non-equivalent in $\mathbf{1}_{\mathrm{L} 2}$ leading to a distorted structure intermediate between trigonal-bipyramidal and squarebased pyramidal. The planarity of the tridentate portion of the ligand is significantly reduced in comparison with $\mathbf{1}_{\mathrm{L} 1}$ [out of plane displacement: $0.31 \AA\left(\mathbf{1}_{\mathrm{L} 2}\right)$ vs. $0.03 \AA\left(\mathbf{1}_{\mathrm{L} 1}\right)$ ]. Overall, a monometallic zinc dichloride species supported by $\mathbf{L} 2$ exhibits a considerable deformation when it is forced to adopt a type-1 conformation.

Secondly, a theoretical study of mono-zinc dichloride complexes bound by respectively $\mathbf{L} 2\left(\mathbf{2}_{\mathrm{L} 2}\right)$ or $\mathbf{L 1}\left(\mathbf{2}_{\mathrm{L} 1}\right)$ in conformations adopted in the structurally characterised nickel bromide complex 2b [Fig. 7(iv)], was undertaken. As a first observation, it is noted that the optimised structure of $\mathbf{2}_{\mathrm{L} 2}$ does not show any noticeable changes when compared with $\mathbf{2 b}$, apart from the expected variation in metal-nitrogen distances [Fig. 7(v) vs. (iv) and Tables 5 and 6]. Indeed, $\mathbf{2}_{\mathrm{L} 2}$ remains in a distorted octahedral geometry with its four nitrogen donor ligands from $\mathbf{L 2}$ occupying the equatorial sites and the halide ligands axial. Two of the $\mathrm{Zn}-\mathrm{N}$ distances are elongated [ $\mathrm{Zn}(1)-\mathrm{N}(1) 2.55 \AA$ and $\mathrm{Zn}(1)-\mathrm{N}(4) 2.54 \AA]$ indicative of a weaker coordination to the metal centre. In addition, the planarity of the pyridine rings within $\mathbf{L} 2$ is reduced when compared with structurally determined $\mathbf{2} \mathbf{b}$ with an increase in the out of plane displacement evident [0.08 (2b) vs. $\left.0.21 \AA\left(\mathbf{2}_{\mathrm{L} 2}\right)\right]$. Nevertheless, based on these observations, it would seem that $\left[(\mathbf{L 2}) \mathrm{ZnCl}_{2}\right]$ when adopting a type-2 conformation is structurally possible. By contrast, the optimised structure for $\left[(\mathbf{L 1}) \mathrm{ZnCl}_{2}\right]\left(\mathbf{2}_{\mathrm{L} 1}\right)$ indicates a more distorted geometry than in $\mathbf{2}_{\mathrm{L} 2}$ [Fig. 7(vi) vs. (v)]. Although the $\mathrm{Zn}(1)-\mathrm{N}(4)$ distance is slightly shorter in this complex [2.44 ( $\left.\mathbf{2}_{\mathrm{L} 1}\right)$ vs. $\left.2.54 \AA\left(\mathbf{2}_{\mathrm{L} 2}\right)\right]$, the $\mathrm{Zn}(1)-\mathrm{N}(1)$ distance is substantially longer $\left[2.70 \AA\left(\mathbf{2}_{\mathrm{L} 1}\right)\right]$, while the out of plane displacement of the pyridine rings is increased further than in $\mathbf{2}_{\mathrm{L} 2}\left[0.37 \AA\left(\mathbf{2}_{\mathrm{L} 1}\right) v s\right.$. $0.21 \AA\left(\mathbf{2}_{\mathrm{L} 2}\right)$ ]. Indeed, the geometry at metal centre in $\boldsymbol{2}_{\mathrm{L} 1}$ could be 


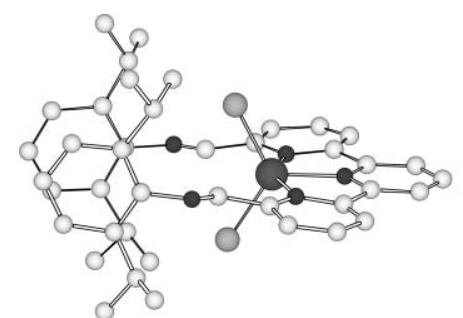

(i) $\left[(\mathbf{L 1}) \mathrm{ZnCl}_{2}\right](\mathbf{1 c})$

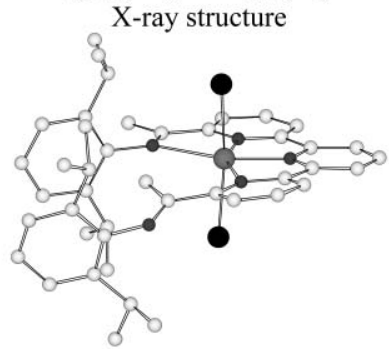

(iv) $\left[(\mathbf{L} 2) \mathrm{NiBr}_{2}\right](\mathbf{2 b})$ $\mathrm{X}$-ray structure

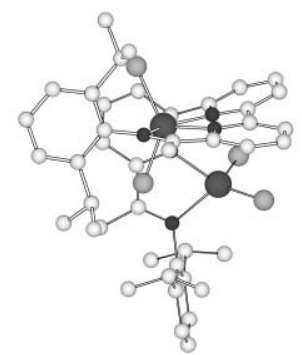

(vii) $\left[(\mathbf{L} 2) \mathrm{Zn}_{2} \mathrm{Cl}_{4}\right](\mathbf{3 c})$ $\mathrm{X}$-ray structure

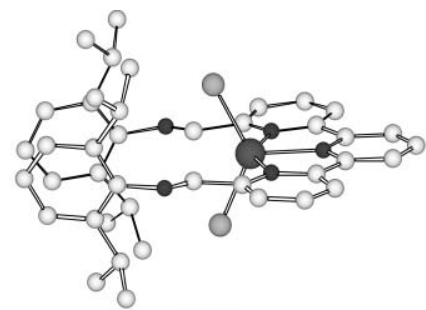

(ii) $\mathbf{1}_{\mathrm{L} 1}$

optimised structure

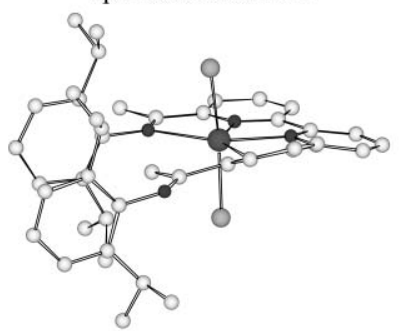

(v) $2_{\mathrm{L} 2}$

optimised structure

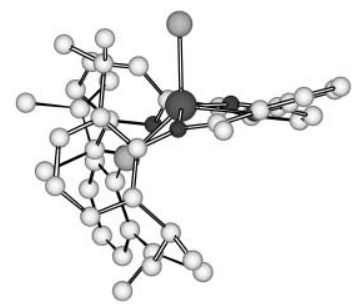

(viii) $4_{\mathrm{L} 2}$

optimised structure

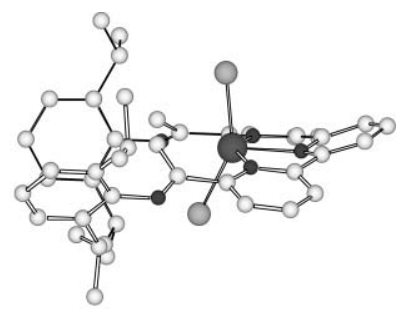

(iii) $\mathbf{1}_{\mathrm{L} 2}$ optimised structure

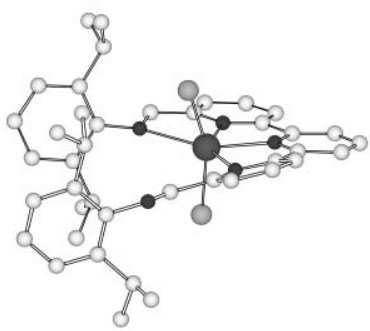

(vi) $2_{\mathrm{L} 1}$

optimised structure

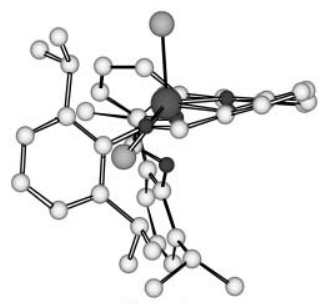

(ix) $4_{\mathrm{L} 1}$

optimised structure

Fig. 7 Calculated structures for $\left[(\mathbf{L} \boldsymbol{x}) \mathrm{ZnCl}_{2}\right]\left(\mathbf{1}_{\mathrm{Lx}}, \mathbf{2}_{\mathrm{L} x}, \mathbf{4}_{\mathrm{Lx}}\right)$ in conformations based on structurally determined $\mathbf{1 c}, \mathbf{2 b}$ and $\mathbf{3 c}$. All hydrogen atoms have been omitted for clarity.

described as more five-coordinate than six-coordinate. Therefore, on comparison of the hypothetical zinc complexes $\mathbf{2}_{\mathrm{L} 2}$ and $\mathbf{2}_{\mathrm{L} 1}$, it would seem that the presence of an endo-oriented imino group stabilises an octahedral-type conformation in the $\mathbf{L} \mathbf{2}$ system while it leads to a significant structural rearrangement for the $\mathbf{L} \mathbf{1}$ system.

Thirdly, to examine the possibility for equilibration of monometallic species in solution (Scheme 4, vide supra) and to probe potential intermediates in the formation of bimetallic species (e.g., 3c), a hypothetical mono-zinc species has been generated by removing one $\mathrm{ZnCl}_{2}$ molecule from structurally characterised 3c. Specifically, we have focused on a conformation $\left(4_{\mathrm{L} 2}\right)$, in which the single $\mathrm{ZnCl}_{2}$ unit is bound in the tridentate iminobipyridine pocket within $\mathbf{L 2}[\mathrm{N}(1), \mathrm{N}(2)$ and $\mathrm{N}(3)]$; the corresponding $\mathbf{4}_{\mathrm{L} 1}$ has also been studied [Fig. 7(viii) and (ix)]. A structural reorganisation is observed on inspection of the theoretical $\left(\mathbf{4}_{\mathrm{Lx}}\right)$ and experimental structures (3c) and consists of a change of the relative positions of the chloride ligands on the metal centre. This structural rearrangement is linked to a permutation in and out of the medium plane of the N(2)- and N(3)-containing pyridine rings. These changes are most likely due to the absence of a second metal centre and the isolated condition of the complex in the theoretical calculations. The most important feature though, is that both theoretical structures do not produce any noticeable structural discrepancies (see Tables 4 and 6) with a difference in bond lengths of $0.04 \AA$ and in angles of $4.2^{\circ}$.

Several points emerge from inspection of the relative energies of the optimised structures established for the mono-zinc dichloride species, $\mathbf{1}_{\mathrm{L} 1}(\mathbf{1 c}), \mathbf{1}_{\mathrm{L} 2}, \mathbf{2}_{\mathrm{L} 2}, \mathbf{2}_{\mathrm{L} 1}, \mathbf{4}_{\mathrm{L} 2}$ and $\mathbf{4}_{\mathrm{L} 1}$ (Table 7). Firstly, a comparison of the $\left[(\mathbf{L 1}) \mathrm{ZnCl}_{2}\right]$ structures indicates that a conformation based on type-1 is substantially preferred to the other two possible conformations $\left[\Delta E=9.56\left(\mathbf{2}_{\mathrm{L} 1}\right)\right.$ and $8.75 \mathrm{kcal} \mathrm{mol}^{-1}$ $\left.\left(\mathbf{4}_{\mathrm{L} 1}\right)\right]$. Secondly, all the $\left[(\mathbf{L 2}) \mathrm{ZnCl}_{2}\right]$ structures display energies

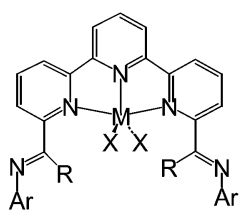

$1_{\mathrm{Lx}}$

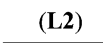

(L1)

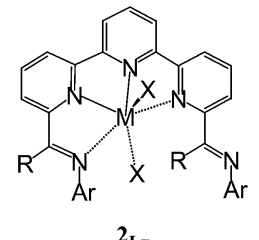

(L2)

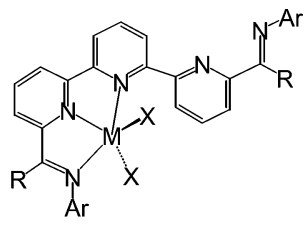

$4_{L x}$

Scheme 4 Possible equilibria for $\left[(\mathbf{L} \boldsymbol{x}) \mathrm{ZnCl}_{2}\right]$ in solution $\left(\mathrm{Ar}=2,6-i-\mathrm{Pr}_{2} \mathrm{C}_{6} \mathrm{H}_{3} ; \mathrm{X}=\right.$ halide $)$. 
Table 7 Relative potential energies $\left(\mathrm{kcal}^{\mathrm{mol}}{ }^{-1}\right)$ for $\left[(\mathbf{L 1}) \mathrm{ZnCl}_{2}\right]$ and $\left[(\mathbf{L 2}) \mathrm{ZnCl}_{2}\right]$ in various conformations; calculations have been performed as $\Delta E\left(E_{\mathrm{y}}-E_{1 \mathrm{~L} x}\right)$

\begin{tabular}{lll}
\hline $\mathbf{y}$ & L1 & L2 \\
\hline $\mathbf{1}_{\mathrm{L} x}$ & 0.0 & 0.0 \\
$\mathbf{2}_{\mathrm{L} x}$ & 9.56 & 1.21 \\
$\mathbf{4}_{\mathrm{L} x}$ & 8.75 & -1.32 \\
\hline
\end{tabular}

that are very close to one another with a slightly more stable conformation apparent for $\mathbf{4}_{\mathrm{L} 2}\left[\Delta E=1.21\left(\mathbf{2}_{\mathrm{L} 2}\right)\right.$ and $-1.32 \mathrm{kcal}$ $\mathrm{mol}^{-1}\left(\mathbf{4}_{\mathrm{L} 2}\right)$ ]. Overall, the data for these species indicate a clear preference for $\left[(\mathbf{L 1}) \mathrm{ZnCl}_{2}\right]$ to exist in a type-1 conformation, while for $\left[(\mathbf{L} 2) \mathrm{ZnCl}_{2}\right]$, the closeness in the relative energies between the different conformations $\left(\mathbf{1}_{\mathrm{L} 2}, \mathbf{2}_{\mathrm{L} 2}, \mathbf{4}_{\mathrm{L} 2}\right)$ suggests that an equilibrium is likely in the gas phase but with a slight preference towards $\mathbf{4}_{\mathrm{L} 2}$. It is worthy of note that for both ligands the type-2 conformation is the least stable of all although, given the accuracy of the theoretical method employed, the significance of this inference should be treated with some caution. However, the isolation and structural characterisation only in the case $\mathrm{NiBr}_{2}$ derivative $\mathbf{2 b}$ suggests that the nature of the halide group may have a stabilising influence for this particular conformation. This will be the subject of further study elsewhere.

In summary, the density functional study carried out on the monometallic $\mathrm{ZnCl}_{2}$ species with $\mathbf{L 1}$ and $\mathbf{L 2}$ as the ligand frame supports the experimental observations and indicates that the nature of the substituent on the imino-carbon moiety has a dramatic effect on the stability of the monometallic species. Several points emerge from the study. Firstly, it is apparent that the difference in the stability of species adopting conformation $\mathbf{1}_{\mathrm{L} x}$ is mainly steric in origin which in turn directly influences the chelating properties around the metal. In the case of L1 steric interactions are minimised while good coordination within the terpyridine moiety is maximised. This stability allied with the substantial reduction of the solvent accessibility to the metal centre in this conformation would appear to suggest why $\mathbf{1}_{\mathrm{L} 1}$ (1c) does not react with a further molecule of $\mathrm{ZnCl}_{2}$ to form a bimetallic complex. Secondly, for $\mathbf{L} 2$, all three conformations $\mathbf{1}_{\mathrm{L} 2}$, $\mathbf{2}_{\mathrm{L} 2}$ and $\mathbf{4}_{\mathrm{L} 2}$ are distorted and can be considered as isoenergetic. These two points together indicate that an equilibrium could be operational in solution for $\mathbf{L} 2$ but not for L1 (Scheme 4). It would be expected, therefore, that further addition of a molecule of $\mathrm{ZnCl}_{2}$ to $\left[(\mathbf{L 2}) \mathrm{ZnCl}_{2}\right.$ ] would drive the equilibrium towards the right hand side and allow occupation of the bidentate pocket in $\mathbf{4}$ to furnish bimetallic complex $\mathbf{3}$.

\section{Conclusions}

The bulky bis(imino)terpyridine ligand $\mathbf{L} \boldsymbol{x}$ has been used as an effective scaffold to support one or two metal(II) halide units. The nature of the imino-carbon substituent is found to have an effect on the number of metal halide units the ligand can bind with the aldimine ligand $\mathbf{L} 1$ showing a strong preference for a single unit while the ketimine $\mathbf{L} 2$ has the capacity to bind one or two metal centres. These experimental results have been further complemented by DFT calculations which reveal that a significant energy gap is apparent for L1-containing systems leading to a stabilised conformation of type-1 and also suggests that dynamic behaviour is likely for L2-supported species leading to bimetallic formation.

\section{Experimental}

\subsection{General}

All reactions, unless otherwise stated, were carried out under an atmosphere of dry, oxygen-free nitrogen, using standard Schlenk techniques or in a nitrogen purged glovebox. Solvents were distilled under nitrogen from appropriate drying agents and degassed prior to use. ${ }^{11}$ The IR spectra were recorded on a Perkin-Elmer Spectrum One FT-IR spectrometer on solid samples. The ES and the FAB mass spectra were recorded using a micromass Quattra LC mass spectrometer and a Kratos Concept spectrometer with methanol or NBA as the matrix respectively. Accurate Mass FABMS were recorded on Kratos Concept spectrometer (xenon gas, $7 \mathrm{kV}$ ) with NBA as matrix. ${ }^{1} \mathrm{H}$ and ${ }^{13} \mathrm{C}$ NMR spectra were recorded on a Bruker ARX spectrometer $(250$ or $300 \mathrm{MHz})$; chemical shifts $(\delta)$ are referred to the residual protic solvent peaks. Magnetic Susceptibility studies were performed using an Evans Balance (Johnson Matthey) at room temperature. The magnetic moments were calculated following standard methods ${ }^{12}$ and corrections for underlying diamagnetism were applied to the data. ${ }^{13}$ Elemental analyses were performed at the Science Technical Support Unit, London Metropolitan University.

The metal dichlorides and $(\mathrm{DME}) \mathrm{NiBr}_{2} \quad(\mathrm{DME}=1,2-$ dimethoxyethane) were purchased from Aldrich Chemical Co. and used without further purification while 2,6-diisopropylaniline was

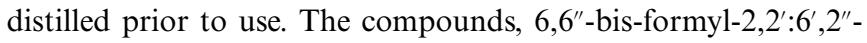
terpyridine ${ }^{5,7}$ and $6,6^{\prime \prime}$-bis-acetyl-2,2':6 $6^{\prime}, 2^{\prime \prime}$-terpyridine ${ }^{5}$ were prepared according to previously reported procedures. All other chemicals were obtained commercially and used without further purification.

\subsection{Synthesis of $6,6^{\prime \prime}$-bis(iminoformyl)-2,2' $: 6^{\prime}, 2^{\prime \prime}$-terpyridine- bis(2,6-diisopropylanil) (L1)}

6,6"-Diformyl-2,2':6', $2^{\prime \prime}$-terpyridine (1.031 g, $\left.3.57 \mathrm{mmol}\right)$ was suspended in absolute ethanol $(20 \mathrm{ml})$ and 2,6-diisopropylaniline ( $1.390 \mathrm{~g}, 7.85 \mathrm{mmol}, 2.2$ eq.) introduced along with a catalytic amount of glacial acetic acid. The mixture was stirred and heated vigorously at $60{ }^{\circ} \mathrm{C}$ for $12 \mathrm{~h}$. The solution was cooled and the resulting precipitate collected by filtration and washed with ethanol $(60 \mathrm{ml})$. The residue was crystallised from a dichloromethanehexane $(1: 9)$ mixture at room temperature and the crystalline material filtered, washed with hexane and dried under vacuum to afford 6,6'- $\left\{\left(2,6-i-\mathrm{Pr}_{2} \mathrm{C}_{6} \mathrm{H}_{3}\right) \mathrm{N}=\mathrm{CH}\right\}_{2}-2,2^{\prime}: 6^{\prime}, 2^{\prime \prime}-\mathrm{C}_{15} \mathrm{H}_{9} \mathrm{~N}_{3}$ (L1) as a pale yellow solid. Yield: $1.411 \mathrm{~g}, 65 \%$. Anal. Calc. for $\mathrm{C}_{41} \mathrm{H}_{45} \mathrm{~N}_{5} \cdot 0.5 \mathrm{H}_{2} \mathrm{O}: \mathrm{C}, 79.87 ; \mathrm{H}, 7.46 ; \mathrm{N}, 11.36 \%$. Found: C, 79.62; $\mathrm{H}, 7.63 ; \mathrm{N}, 10.81 \% .{ }^{1} \mathrm{H}$ NMR $\left(300 \mathrm{MHz}, \mathrm{CDCl}_{3}\right): \delta 1.14\left(\mathrm{~d},{ }^{3} J_{\mathrm{H}-\mathrm{H}}\right.$ 7.0, 24H, $\left.\mathrm{CH}\left(\mathrm{CH}_{3}\right)_{2}\right), 2.92$ (sept, $\left.{ }^{3} J_{\mathrm{H}-\mathrm{H}} 7.0,4 \mathrm{H}, \mathrm{CH}\left(\mathrm{CH}_{3}\right)_{2}\right), 7.03-$ $7.16(\mathrm{~m}, 6 \mathrm{H}, \mathrm{Ar}-\mathrm{H}), 7.91$ (app. t, $\left.{ }^{3} J_{\mathrm{H}-\mathrm{H}} 7.6,{ }^{3} J_{\mathrm{H}-\mathrm{H}} 7.6,1 \mathrm{H}, \mathrm{Py}-\mathrm{H}\right)$, 7.96 (app. t, $\left.{ }^{3} J_{\mathrm{H}-\mathrm{H}} 7.9,{ }^{3} J_{\mathrm{H}-\mathrm{H}} 7.9,2 \mathrm{H}, \mathrm{Py}-\mathrm{H}\right), 8.29\left(\mathrm{~d},{ }^{3} J_{\mathrm{H}-\mathrm{H}} 7.6,2 \mathrm{H}\right.$, $\mathrm{Py}-\mathrm{H}), 8.36(\mathrm{~s}, 2 \mathrm{H}, \mathrm{HC}=\mathrm{N}), 8.52\left(\mathrm{~d},{ }^{3} J_{\mathrm{H}-\mathrm{H}} 7.9,2 \mathrm{H}, \mathrm{Py}-\mathrm{H}\right)$ and 8.71 $\left(\mathrm{d},{ }^{3} J_{\mathrm{H}-\mathrm{H}} 7.6,2 \mathrm{H}, \mathrm{Py}-\mathrm{H}\right) .{ }^{13} \mathrm{C}\left\{{ }^{1} \mathrm{H}\right\} \mathrm{NMR}\left(75 \mathrm{MHz}, \mathrm{CDCl}_{3}\right): \delta 23.5$ $\left(\mathrm{CH}_{3}\right), 28.0(\mathrm{CH}), 121.1$ (Py), 121.4 (Py), 122.7 (Py), 122.8 (Py), 123.1 (Ar), 124.5 (Ar), 137.3 (Py), 137.6 (Py), 148.6 (Ar), 154.0 (Ar), $155.0(\mathrm{Py}), 156.1(\mathrm{Py})$ and $163.5(\mathrm{C}=\mathrm{N}) . \mathrm{IR}\left(\mathrm{cm}^{-1}\right): 2952(\mathrm{~m})$, 
1648(m, $v(\mathrm{C}=\mathrm{N})), 1563(\mathrm{~s}), 1434(\mathrm{~s}), 1361(\mathrm{w}), 1190(\mathrm{w}), 1115(\mathrm{~s})$, 795(s), 786(s) and 760(s). ESI positive mass spectrum $(\mathrm{m} / \mathrm{z}): 608$ $\left[(\mathrm{M}+\mathrm{H})^{+}\right]$. Acc. Mass FABMS positive spectrum $(\mathrm{m} / \mathrm{z})$ : required for $\left(\mathrm{C}_{43} \mathrm{H}_{49} \mathrm{~N}_{5} \mathrm{H}^{+}\right)$608.37532. Found 608.37532. Mp 220-222 ${ }^{\circ} \mathrm{C}$.

\subsection{Synthesis of 6,6"-bis(iminoacetyl)-2,2':6', 2'-terpyridine- bis(2,6-diisopropylanil) (L2)}

6,6'-Diacetyl-2,2':6',2"-terpyridine $(1.00 \mathrm{~g}, 3.15 \mathrm{mmol})$ was suspended in absolute ethanol $(16 \mathrm{ml})$ and 2,6-diisopropylaniline (1.228 g, $6.94 \mathrm{mmol}, 2.2$ eq.) introduced along with a catalytic amount of formic acid $(98 \%)$. The mixture was stirred and heated vigorously at $100{ }^{\circ} \mathrm{C}$ for $36 \mathrm{~h}$. The solution was cooled and the resulting precipitate collected by filtration and washed with ethanol $(60 \mathrm{ml})$. The residue was crystallised from a dichloromethane-hexane (1:9) mixture at room temperature and the resulting crystalline material filtered, washed with hexane and dried under vacuum to afford $6,6^{\prime \prime}-\left\{\left(2,6-i-\mathrm{Pr}_{2} \mathrm{C}_{6} \mathrm{H}_{3}\right) \mathrm{N}=\mathrm{CMe}\right\}_{2}$ $2,2^{\prime}: 6^{\prime}, 2^{\prime \prime}-\mathrm{C}_{15} \mathrm{H}_{9} \mathrm{~N}_{3}(\mathbf{L 2})$ as a pale yellow solid. Yield: $1.10 \mathrm{~g}, 55 \%$. Anal. Calc. for $\mathrm{C}_{43} \mathrm{H}_{49} \mathrm{~N}_{5}: \mathrm{C}, 81.26 ; \mathrm{H}, 7.72 ; \mathrm{N}, 11.02 \%$. Found: C, $81.16 ; \mathrm{H}, 7.86 ; \mathrm{N}, 10.92 \% .{ }^{1} \mathrm{H}$ NMR $\left(300 \mathrm{MHz}, \mathrm{CDCl}_{3}\right): \delta$ $1.11\left(\mathrm{~d},{ }^{3} J_{\mathrm{H}-\mathrm{H}} 6.7,24 \mathrm{H}, \mathrm{CH}\left(\mathrm{CH}_{3}\right)_{2}\right), 2.29\left(\mathrm{~s}, 6 \mathrm{H}, \mathrm{CH}_{3} \mathrm{C}=\mathrm{N}\right), 2.72$ (sept, $\left.{ }^{3} J_{\mathrm{H}-\mathrm{H}} 6.7,4 \mathrm{H}, \mathrm{CH}\left(\mathrm{CH}_{3}\right)_{2}\right), 7.0-7.1(\mathrm{~m}, 6 \mathrm{H}, \mathrm{Ar}-\mathrm{H}), 7.91$ (app. t, ${ }^{3} J_{\mathrm{H}-\mathrm{H}} 7.9,{ }^{3} J_{\mathrm{H}-\mathrm{H}} 7.9,1 \mathrm{H}, \mathrm{Py}-\mathrm{H}$ ), 7.92 (app. t, ${ }^{3} J_{\mathrm{H}-\mathrm{H}} 7.9$, $\left.{ }^{3} J_{\mathrm{H}-\mathrm{H}} 7.9,2 \mathrm{H}, \mathrm{Py}-\mathrm{H}\right), 8.37\left(\mathrm{dd},{ }^{3} J_{\mathrm{H}-\mathrm{H}} 7.9,{ }^{4} J_{\mathrm{H}-\mathrm{H}} 0.9,2 \mathrm{H}, \mathrm{Py}-\mathrm{H}\right)$, $8.54\left(\mathrm{~d},{ }^{3} J_{\mathrm{H}-\mathrm{H}} 7.9,2 \mathrm{H}, \mathrm{Py}-\mathrm{H}\right)$ and $8.71\left(\mathrm{dd},{ }^{3} J_{\mathrm{H}-\mathrm{H}} 7.9,{ }^{4} J_{\mathrm{H}-\mathrm{H}} 0.9\right.$, $2 \mathrm{H}, \mathrm{Py}-\mathrm{H}) .{ }^{13} \mathrm{C}\left\{{ }^{1} \mathrm{H}\right\} \mathrm{NMR}\left(75 \mathrm{MHz}, \mathrm{CDCl}_{3}\right): \delta 16.3\left(\mathrm{CH}_{3} \mathrm{C}=\mathrm{N}\right)$, $21.9\left(\mathrm{CH}_{3}\right), 22.2\left(\mathrm{CH}_{3}\right), 27.3(\mathrm{CH}), 120.0(\mathrm{Py}), 120.3(\mathrm{Py}), 121.0$ (Py), 122.0 (Ar), 122.6 (Ar), 134.8 (Ar), 136.3 (Py), 136.8 (Py), 145.5 (Рy), 136.3 (Py), 136.8 (Py), 145.4 (Ar), 154.0 (Py), 154.2 (Py), $154.6(\mathrm{Py})$ and $166.1(\mathrm{C}=\mathrm{N})$. IR $\left(\mathrm{cm}^{-1}\right)$ : 2960(m), 1642(m, $v(\mathrm{C}=\mathrm{N})), 1563(\mathrm{~s}), 1430(\mathrm{~s}), 1362(\mathrm{w}), 1256(\mathrm{w}), 1184(\mathrm{w}), 1108(\mathrm{~m})$, 800(s), 784(s) and 760(s). ESI positive mass spectrum $(\mathrm{m} / \mathrm{z}): 636$ $\left[(\mathrm{M}+\mathrm{H})^{+}\right] . \mathrm{Mp} 252-254^{\circ} \mathrm{C}$.

\subsection{Synthesis of $\left[6,6^{\prime \prime}\right.$-bis(iminoformyl)-2,2':6', $2^{\prime \prime}$-terpyridine- bis(2,6-diisopropylanil)]MX $\mathbf{M}_{2}$ (1)}

(a) $1 \mathrm{a}, \mathbf{M}=\mathrm{Fe}, \mathbf{X}=\mathbf{C l}$. An oven-dried Schlenk flask equipped with a magnetic stir bar was evacuated and backfilled with nitrogen. The flask was charged with anhydrous $\mathrm{FeCl}_{2}$ $(0.021 \mathrm{~g}, 0.164 \mathrm{mmol})$ in $n-\mathrm{BuOH}(10 \mathrm{ml})$ and the contents stirred at $110^{\circ} \mathrm{C}$ until the iron salt had completely dissolved. $\mathbf{L 1}(0.100 \mathrm{~g}$, $0.164 \mathrm{mmol}, 1 \mathrm{eq}$.) was added and the mixture heated to $110^{\circ} \mathrm{C}$ for a further $20 \mathrm{~min}$. After cooling to room temperature, the suspension was concentrated and washed several times with hexane. The solid was dried overnight under reduced pressure to afford [6,6"$\left.\left\{\left(2,6-i-\mathrm{Pr}_{2} \mathrm{C}_{6} \mathrm{H}_{3}\right) \mathrm{N}=\mathrm{CH}\right\}_{2}-2,2^{\prime}: 6^{\prime}, 2^{\prime \prime}-\mathrm{C}_{15} \mathrm{H}_{9} \mathrm{~N}_{3}\right] \mathrm{FeCl}_{2}$ (1a) as a redbrown solid. Crystallisation of 1a from hot acetonitrile solution gave 1a as red needles. Yield: $0.096 \mathrm{~g}, 80 \%$. Anal. Calc. for $\mathrm{C}_{41} \mathrm{H}_{45} \mathrm{~N}_{5} \mathrm{FeCl}_{2} \cdot 1.5 \mathrm{H}_{2} \mathrm{O} \cdot 0.5 \mathrm{MeCN}$ : C, 64.49; H, 6.35; N, 9.85\%. Found: C, 64.78; H, 6.06; N, 9.63\%.

(b) $\mathbf{1 b}, \mathbf{M}=\mathbf{N i}, \mathbf{X}=\mathbf{B r}$. Using an analogous procedure to that described in 4.4(a) employing (DME) $\mathrm{NiBr}_{2}(0.051 \mathrm{~g}$, $0.164 \mathrm{mmol})$ and $\mathbf{L 1}(0.100 \mathrm{~g}, 0.164 \mathrm{mmol}, 1$ eq. $)$ gave [6, 6 " $^{\prime \prime}\{(2,6-i-$ $\left.\left.\left.\mathrm{Pr}_{2} \mathrm{C}_{6} \mathrm{H}_{3}\right) \mathrm{N}=\mathrm{CH}\right\}_{2}-2,2^{\prime}: 6^{\prime}, 2^{\prime \prime}-\mathrm{C}_{15} \mathrm{H}_{9} \mathrm{~N}_{3}\right] \mathrm{NiBr}_{2}(\mathbf{1 b})$ as a yellow solid. Crystallisation of $\mathbf{1 b}$ from hot acetonitrile solution gave $\mathbf{1 b}$ as yellow needles. Yield: $0.108 \mathrm{~g}, 80 \%$. Anal. Calc. for $\mathrm{C}_{41} \mathrm{H}_{45} \mathrm{~N}_{5} \mathrm{NiBr}_{2}$ : C, 59.59; H, 5.45; N, 8.48\%. Found: C, 59.50; H, 5.61; N, 8.39\%. (c) $\mathbf{1 c}, \mathbf{M}=\mathbf{Z n}, \mathbf{X}=\mathbf{C l}$. Using an analogous procedure to that described in 4.4(a) employing anhydrous $\mathrm{ZnCl}_{2}(0.022 \mathrm{~g}$, $0.164 \mathrm{mmol})$ and $\mathbf{L 1}(0.100 \mathrm{~g}, 0.164 \mathrm{mmol}, 1$ eq. $)$ gave [6, $6^{\prime \prime}-\{(2,6-i-$ $\left.\left.\left.\mathrm{Pr}_{2} \mathrm{C}_{6} \mathrm{H}_{3}\right) \mathrm{N}=\mathrm{CH}\right\}_{2}-2,2^{\prime}: 6^{\prime}, 2^{\prime \prime}-\mathrm{C}_{15} \mathrm{H}_{9} \mathrm{~N}_{3}\right] \mathrm{ZnCl}_{2}(\mathbf{1 c})$ as a yellow solid. Crystallisation of 1c from a mixture of acetonitrile/chloroform gave 1c as yellow needles. Yield: $0.085 \mathrm{~g}, 70 \%$. Anal. Calc. for $\mathrm{C}_{41} \mathrm{H}_{45} \mathrm{~N}_{5} \mathrm{ZnCl}_{2} \cdot 1 / 3 \mathrm{CHCl}_{3}$ : C, 63.33; H, 5.79; N, 8.94\%. Found: C, $62.99 ; \mathrm{H}, 5.72 ; \mathrm{N}, 8.91 \%$.

\subsection{Synthesis of $\left[6,6^{\prime \prime}\right.$-bis(iminoacetyl)-2,2' $: 6^{\prime}, 2^{\prime \prime}$-terpyridine- bis(2,6-diisopropylanil)] $\mathrm{NiBr}_{2}$ (2b)}

Under an atmosphere of nitrogen a mixture of $\mathbf{L 2}(0.178 \mathrm{~g}$, $0.280 \mathrm{mmol})$ and (DME) $\mathrm{NiBr}_{2}(0.086 \mathrm{~g}, 0.280 \mathrm{mmol}, 1$ eq.) were added to a Schlenk flask containing dichloromethane $(10 \mathrm{ml})$ at $0{ }^{\circ} \mathrm{C}$. The stirred reaction mixture was allowed to warm to room temperature and stirring continued for a further $12 \mathrm{~h}$. The volatiles were removed under reduced pressure and the residue was washed with hexane $(20 \mathrm{ml})$ to yield $\left[6,6^{\prime \prime}-\left\{\left(2,6-i-\mathrm{Pr}_{2} \mathrm{C}_{6} \mathrm{H}_{3}\right) \mathrm{N}=\mathrm{CH}\right\}_{2}-\right.$ $\left.2,2^{\prime}: 6^{\prime}, 2^{\prime \prime}-\mathrm{C}_{15} \mathrm{H}_{9} \mathrm{~N}_{3}\right] \mathrm{NiBr}_{2}(\mathbf{2 b})$ as a yellow solid. Crystallisation of 2b from a mixture of acetonitrile-chloroform gave $\mathbf{2 b}$ as yellow blocks. Yield: 0.167 g, $70 \%$. Anal. Calc. for $\mathrm{C}_{43} \mathrm{H}_{49} \mathrm{~N}_{5} \mathrm{NiBr}_{2}$ : C, $60.39 ;$ H, 5.73; N, 8.19\%. Found: C, 60.23; H, 5.92; N, 7.99\%.

\subsection{Synthesis of $\left[6,6^{\prime \prime}\right.$-bis(iminoacetyl)-2,2':6', $2^{\prime \prime}$-terpyridine- bis(2,6-diisopropylanil) $\mid M_{2} X_{4}(3)$}

(a) 3a, $\mathbf{M}=\mathbf{F e}, \mathbf{X}=\mathbf{C l}$. An oven-dried Schlenk flask equipped with a magnetic stir bar was evacuated and backfilled with nitrogen. The flask was charged with anhydrous $\mathrm{FeCl}_{2}$ $(0.040 \mathrm{~g}, 0.315 \mathrm{mmol})$ in $n-\mathrm{BuOH}(10 \mathrm{ml})$ and the contents stirred at $110{ }^{\circ} \mathrm{C}$ until the iron salt had completely dissolved. L2 $(0.100 \mathrm{~g}, 0.157 \mathrm{mmol}, 0.5 \mathrm{eq}$.) was added and the mixture heated to $110^{\circ} \mathrm{C}$ for a further $20 \mathrm{~min}$. After cooling to room temperature, the suspension was concentrated and washed several times with hexane. The solid was dried overnight under reduced pressure to afford $\left[6,6^{\prime \prime}-\left\{\left(2,6-i-\mathrm{Pr}_{2} \mathrm{C}_{6} \mathrm{H}_{3}\right) \mathrm{N}=\mathrm{CMe}\right\}_{2}-2,2^{\prime}: 6^{\prime}, 2^{\prime \prime}-\mathrm{C}_{15} \mathrm{H}_{9} \mathrm{~N}_{3}\right] \mathrm{Fe}_{2} \mathrm{Cl}_{4}$ (3a) as a brown solid. Crystallisation of $\mathbf{3 a}$ from hot acetonitrile solution gave 3a as red blocks. Yield: $0.109 \mathrm{~g}, 78 \%$.

(b) $3 b, M=N i, X=B r$. Using an analogous procedure to that described in 4.6(a) employing (DME) $\mathrm{NiBr}_{2}(0.097 \mathrm{~g}$, $0.315 \mathrm{mmol})$ and $\mathbf{L 2}(0.100 \mathrm{~g}, 0.157 \mathrm{mmol}, 0.5$ eq. $)$ gave [6, $6^{\prime \prime}-\{(2,6-$ $i$ - $\left.\left.\left.\mathrm{Pr}_{2} \mathrm{C}_{6} \mathrm{H}_{3}\right) \mathrm{N}=\mathrm{CMe}\right\}_{2}-2,2^{\prime}: 6^{\prime}, 2^{\prime \prime}-\mathrm{C}_{15} \mathrm{H}_{9} \mathrm{~N}_{3}\right] \mathrm{Ni}_{2} \mathrm{Br}_{4}(\mathbf{3 b})$ as an orange solid. Yield: $0.135 \mathrm{~g}, 80 \%$. Crystallisation of $\mathbf{3 b}$ by prolonged standing in chloroform gave $\mathbf{3 b}\left(\mathrm{H}_{2} \mathrm{O}\right)$ as green needles.

(c) $3 c, \mathbf{M}=\mathbf{Z n}, \mathbf{X}=\mathbf{C l}$. Using an analogous procedure to that described in 4.6(a) employing anhydrous $\mathrm{ZnCl}_{2}(0.043 \mathrm{~g}$, $0.315 \mathrm{mmol})$ and $\mathbf{L 2}(0.100 \mathrm{~g}, 0.157 \mathrm{mmol}, 0.5$ eq. $)$ gave [6, $6^{\prime \prime}-\{(2,6-$ $i$ - $\left.\left.\left.\mathrm{Pr}_{2} \mathrm{C}_{6} \mathrm{H}_{3}\right) \mathrm{N}=\mathrm{CMe}\right\}_{2}-2,2^{\prime}: 6^{\prime}, 2^{\prime \prime}-\mathrm{C}_{15} \mathrm{H}_{9} \mathrm{~N}_{3}\right] \mathrm{Zn}_{2} \mathrm{Cl}_{4}(\mathbf{3 c})$ as a yellow solid. Crystallisation of $\mathbf{3} \mathbf{c}$ from hot acetonitrile solution gave $\mathbf{1 b}$ as yellow plates. Yield: $0.107 \mathrm{~g}, 75 \%$. Anal. Calc. for $\mathrm{C}_{43} \mathrm{H}_{49} \mathrm{~N}_{5} \mathrm{Zn}_{2} \mathrm{Cl}_{4}$. C, 56.84; H, 5.40; N, 7.71\%. Found: C, 56.96; H, 5.48; N, 7.68\%.

\subsection{Conversion of $2 \mathrm{~b}$ to $3 \mathrm{~b}$}

An oven-dried Schlenk flask equipped with a magnetic stir bar was evacuated and backfilled with nitrogen. The flask was charged with (DME) $\mathrm{NiBr}_{2}(0.048 \mathrm{~g}, 0.157 \mathrm{mmol})$ and $n-\mathrm{BuOH}$ $(10 \mathrm{ml})$ and the suspension heated to $110{ }^{\circ} \mathrm{C}$ until the nickel 


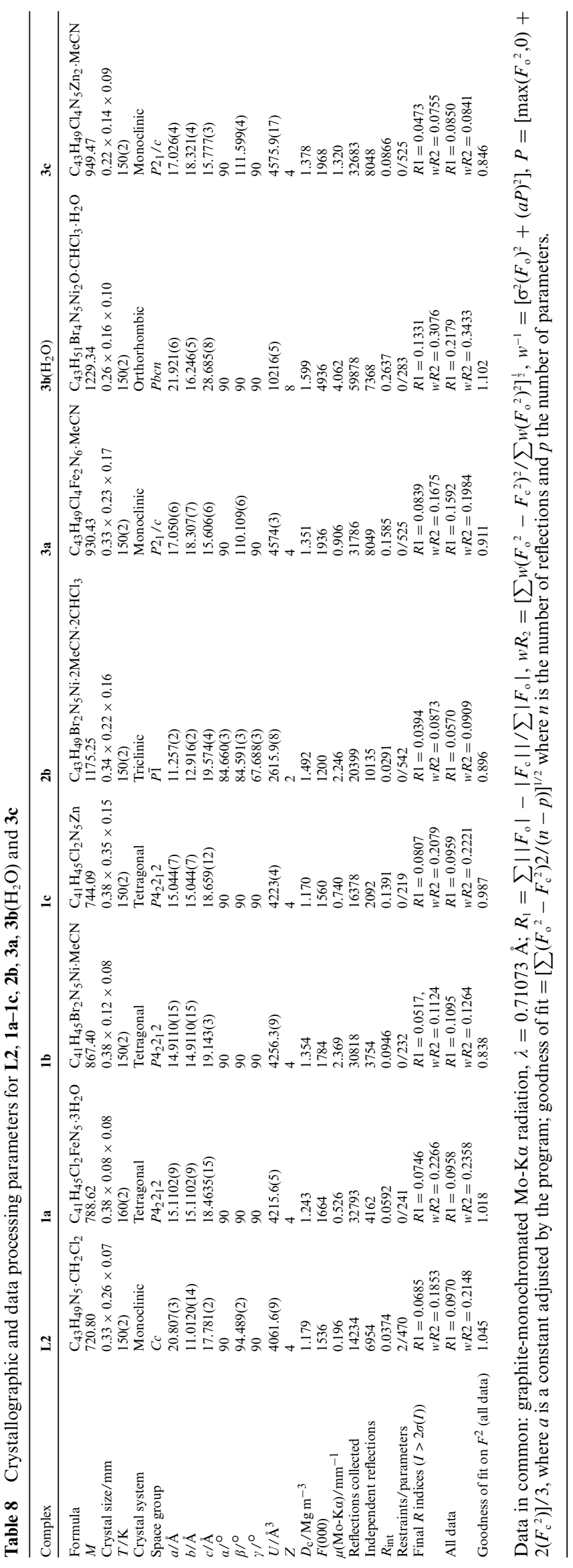

salt had partially dissolved. 2 b $(0.134 \mathrm{~g}, 0.157 \mathrm{mmol}, 1$ eq. $)$ was added and the mixture heated to $110{ }^{\circ} \mathrm{C}$ for a further $30 \mathrm{~min}$. After cooling to room temperature, the suspension was concentrated and washed several times with hexane. The solid was dried overnight under reduced pressure to afford $\left[6,6^{\prime \prime}-\{(2,6-\right.$ $i$ - $\left.\left.\left.\mathrm{Pr}_{2} \mathrm{C}_{6} \mathrm{H}_{3}\right) \mathrm{N}=\mathrm{CMe}\right\}_{2}-2,2^{\prime}: 6^{\prime}, 2^{\prime \prime}-\mathrm{C}_{15} \mathrm{H}_{9} \mathrm{~N}_{3}\right] \mathrm{Ni}_{2} \mathrm{Br}_{4}(\mathbf{3 b})$ as an orange solid. Yield: $0.143 \mathrm{~g}, 85 \%$.

\subsection{Density functional calculations}

Quantum mechanical calculations have been carried out using the Gaussian 03 package of programs. ${ }^{14}$ The density functional theory (DFT) was applied, in particular the functional Becke's three-parameter hybrid exchange method combined with LYP correlation functional (B3LYP). ${ }^{15}$ The quasi-relativistic effective core potential (ECP) LANL2DZ was used for the metal atoms $(\mathrm{Zn}){ }^{16}$ The basis set for both atoms in the valence double- $\zeta$ contraction associated to this ECP. ${ }^{14,16}$ The valence double- $\zeta$ with polarisation $6-31 \mathrm{G}(\mathrm{d})^{17,18}$ basis was used for $\mathrm{N}$ and $\mathrm{Cl}$ and the minimal basis STO-3G for $\mathrm{C}$ and $\mathrm{H}$.

\subsection{Crystallography}

Data for L2, 1a-1c 2b, 3a, 3b $\left(\mathrm{H}_{2} \mathrm{O}\right)$ and 3c were collected on a Bruker APEX 2000 CCD diffractometer. Details of data collection, refinement and crystal data are listed in Table 8 . The data were corrected for Lorentz and polarisation effects and empirical absorption corrections applied. Structure solution by direct methods and structure refinement on $F^{2}$ employed SHELXTL version 6.10. ${ }^{19}$ Hydrogen atoms were included in calculated positions $(\mathrm{C}-\mathrm{H}=0.96 \AA)$ riding on the bonded atom with isotropic displacement parameters set to $1.5 U_{\mathrm{eq}}(\mathrm{C})$ for methyl $\mathrm{H}$ atoms and $1.2 U_{\text {eq }}(\mathrm{C})$ for all other $\mathrm{H}$ atoms. With the exception of $\mathbf{3 b}\left(\mathrm{H}_{2} \mathrm{O}\right)$ (only $\mathrm{Ni}$ and $\mathrm{Br}$ refined anisotropically) and $\mathbf{1 c}$ (all atoms apart from $\mathrm{C} 21$ and $\mathrm{C} 9$ ), all non- $\mathrm{H}$ atoms were refined with anisotropic displacement parameters. Disordered $\mathrm{MeCN}$ was omitted using the SQUEEZE option in PLATON for $\mathbf{1 b}$ and $\mathbf{2 b}$.

CCDC reference numbers 289324-289331.

For crystallographic data in CIF or other electronic format see DOI: $10.1039 / \mathrm{b} 516083 \mathrm{a}$

\section{Acknowledgements}

We thank the University of Leicester for financial assistance. ExxonMobil Chemical are also thanked for Undergraduate summer Bursaries (to I. D. and D. P.).

\section{References}

1 For a review, see: C. Piguet, G. Bernardinelli and G. Hopfgartner, Chem. Rev., 1997, 97, 2005.

2 (a) E. C. Constable, S. M. Elder, P. R. Raithby and M. D. Ward, Polyhedron, 1991, 10, 1395; (b) E. C. Constable, M. Neuburger, L. A. Whall and M. Zehnder, New J. Chem., 1998, 22, 219.

3 (a) K. T. Potts, M. Keshavarz, K. F. S. Tham, H. D. Abruna and C. Arana, Inorg. Chem., 1993, 32, 4436; (b) E. C. Constable, M. A. M. Daniels, M. G. B. Drew, D. A. Tocher, J. V. Walker and P. D. Wood, J. Chem. Soc., Dalton Trans., 1993, 1947; (c) E. C. Constable, M. D. Ward, M. G. B. Drew and G. A. Forsyth, Polyhedron, 1989, 8, 2551.

4 (a) K. T. Potts, M. Keshavarz-K, F. S. Tham, H. D. Abruna and C. R. Arana, Inorg. Chem., 1993, 32, 4422; (b) E. C. Constable, M. G. B. Drew and M. D. Ward, J. Chem. Soc., Chem. Commun., 1987, 1600; (c) M. Barley, E. C. Constable, S. A. Corr, R. C. S. McQueen, J. C. Nutkins, 
M. D. Ward and M. G. B. Drew, J. Chem. Soc., Dalton Trans., 1988, 2655; (d) K. T. Potts, M. Keshavarz-K, F. S. Tham, H. D. Abruna and C. Arana, Inorg. Chem., 1993, 32, 4436; (e) W. Dai, H. Hu, X. Wei, S. Zhu, D. Wang, K. Yu, N. K. Dalley and X. Kou, Polyhedron, 1997, 16, 2059.

5 Y. D. M. Champouret, R. K. Chaggar, I. Dadhiwala, J. Fawcett and G. A. Solan, Tetrahedron, 2006, $62,79$.

6 A. El-ghayouy, A. Harriman, A. De Cian, J. Fischer and R. Ziessel, J. Am. Chem. Soc., 1998, 120, 9973.

7 A. El-ghayoury, Z. Abdelkrim and R. Ziessel, J. Org. Chem., 2000, 65, 775.

8 K. T. Potts, K. A. Cheysen Raiford and M. Keshavarz-K, J. Am. Chem. Soc., 1993, 115, 2793.

9 A. Gerli, K. S. Hagen and L. G. Marzilli, Inorg. Chem., 1991, 30, 4673.

10 For use of the $v(\mathrm{CO})$ stretch as a guide to relative donor capability of imines, see: (a) M. Brockmann, H. tom Dieck and J. Klaus, J. Organomet. Chem., 1986, 301, 209; (b) S. Morton and J. F. Nixon, J. Organomet. Chem., 1985, 282, 123; (c) L. Gonsalvi, J. A. Gaunt, H. Adams, A. Castro, G. J. Sunley and A. Haynes, Organometallics, 2003, 22, 1047.

11 W. L. F. Armarego and D. D. Perrin, Purification of Laboratory Chemicals, Butterworth Heinemann, London, 4th edn, 1996.

12 F. E. Mabbs and D. J. Machin, Magnetism and Transition Metal Complexes, Chapman and Hall, London, 1973.

13 (a) C. J. O'Connor, Prog. Inorg. Chem., 1982, 29, 203; (b) Handbook of Chemistry and Physics, ed. R. C. Weast, CRC Press, Boca Raton, FL, 70th edn, 1990, p. E134.
14 M. J. Frisch, G. W. Trucks, H. B. Schlegel, G. E. Scuseria, M. A. Robb, J. R. Cheeseman, J. A. Montgomery, Jr., T. Vreven, K. N. Kudin, J. C. Burant, J. M. Millam, S. S. Iyengar, J. Tomasi, V. Barone, B. Mennucci, M. Cossi, G. Scalmani, N. Rega, G. A. Petersson, H. Nakatsuji, M. Hada, M. Ehara, K. Toyota, R. Fukuda, J. Hasegawa, M. Ishida, T. Nakajima, Y. Honda, O. Kitao, H. Nakai, M. Klene, X. Li, J. E. Knox, H. P. Hratchian, J. B. Cross, C. Adamo, J. Jaramillo, R. Gomperts, R. E. Stratmann, O. Yazyev, A. J. Austin, R. Cammi, C. Pomelli, J. W. Ochteriski, P. Y. Ayala, K. Morokuma, G. A. Voth, P. Salvador, J. J. Dannenberg, V. G. Zakrzewski, S. Dapprich, A. D. Daniels, M. C. Strain, O. Farkas, D. K. Malick, A. D. Rabuck, K. Raghavachari, J. B. Foresman, J. V. Ortiz, Q. Cui, A. G. Baboul, S. Clifford, J. Cioslowski, B. B. Stefanov, G. Liu, A. Liashenko, P. Piskorz, I. Komaromi, R. L. Martin, D. J. Fox, T. Keith, M. A. Al-Laham, C. Y. Peng, A. Nanayakkara, M. Challacombe, P. M. W. Gill, B. Johnson, W. Chen, M. W. Wong, C. Gonzalez, and J. A. Pople, Gaussian 03 (Revision C.02), Gaussian, Inc., Wallingford, CT, 2004

15 (a) A. D. Becke, J. Chem. Phys., 1993, 98, 5648; (b) C. Lee, W. Yang and R. G. Parr, Phys. Rev. B: Condens. Matter, 1988, 37, 785; (c) P. J. Stephens, F. J. Devlin, C. F. Chabalowski and M. J. Frisch, J. Phys. Chem., 1994, 98, 11623.

16 P. J. Hay and W. R. Wadt, J. Chem. Phys., 1985, 82, 299.

17 W. J. Hehre, R. Ditchfield and J. A. Pople, J. Chem. Phys., 1972, 56, 2257.

18 P. C. Hariharan and J. A. Pople, Theor. Chim. Acta, 1973, 28, 213.

19 G. M. Sheldrick, SHELXTL, Version 6.10, Bruker AXS, Inc., Madison, WI, USA, 2000. 